\title{
LIGHT-DUTY VEHICLES
}

Non-Cost Barriers to Consumer Adoption of New Light-Duty Vehicle Technologies 



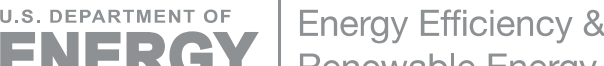 \\ Renewable Energy
}

\section{Transportation Energy Futures Series: Non-Cost Barriers to Consumer Adoption of New Light-Duty Vehicle Technologies}

\author{
A Study Sponsored by \\ U.S. Department of Energy \\ Office of Energy Efficiency and Renewable Energy
}

March 2013

Prepared by

ARGONNE NATIONAL LABORATORY

Argonne, Illinois 60439

managed by

U Chicago Argonne, LLC

for the

\section{U.S. DEPARTMENT OF ENERGY}

under contract DE-AC02-06CH11357

This report was prepared as an account of work sponsored by an agency of the United States Government. Neither the United States Government nor any agency thereof, nor any of their employees, makes any warranty, expressed or implied, or assumes any legal liability or responsibility for the accuracy, completeness, or usefulness of any information, apparatus, product, or process disclosed, or represents that its use would not infringe privately owned rights. Reference herein to any specific commercial product, process, or service by trade name, trademark, manufacturer, or otherwise, does not necessarily constitute or imply its endorsement, recommendation, or favoring by the United States Government or any agency thereof. The views and opinions of authors expressed herein do not necessarily state or reflect those of the United States Government or any agency thereof. 


\section{About the Transportation Energy futures Project}

This is one of a series of reports produced as a result of the Transportation Energy Futures (TEF) project, a U.S. Department of Energy (DOE)-sponsored multi-agency project initiated to identify underexplored strategies for abating greenhouse gases and reducing petroleum dependence related to transportation. The project was designed to consolidate existing transportation energy knowledge, advance analytic capacity-building, and uncover opportunities for sound strategic action.

Transportation currently accounts for $71 \%$ of total U.S. petroleum use and $33 \%$ of the nation's total carbon emissions. The TEF project explores how combining multiple strategies could reduce GHG emissions and petroleum use by $80 \%$. Researchers examined four key areas - lightduty vehicles, non-light-duty vehicles, fuels, and transportation demand - in the context of the marketplace, consumer behavior, industry capabilities, technology and the energy and transportation infrastructure. The TEF reports support DOE long-term planning. The reports provide analysis to inform decisions about transportation energy research investments, as well as the role of advanced transportation energy technologies and systems in the development of new physical, strategic, and policy alternatives.

In addition to the DOE and its Office of Energy Efficiency and Renewable Energy, TEF benefitted from the collaboration of experts from the National Renewable Energy Laboratory and Argonne National Laboratory, along with steering committee members from the Environmental Protection Agency, the Department of Transportation, academic institutions and industry associations. More detail on the project, as well as the full series of reports, can be found at http://www.eere.energy.gov/analysis/transportationenergyfutures.

Contract Nos.

DC-A36-08GO28308 and DE-AC02-06CH11357 


\section{AVAILABILITY}

This report is available electronically at http://www.osti.gov/bridge

Available for a processing fee to U.S. Department of Energy and its contractors, in paper form, from:

U.S. Department of Energy Office of Scientific and Technical Information

P.O. Box 62

Oak Ridge, TN 37831-0062

phone: 865.576 .8401

fax: 865.576 .5728

email: reports@adonis.osti
Available for sale to the public, in paper form, from:

U.S. Department of Commerce

National Technical Information Service 5285 Port Royal Road Springfield, VA 22161

phone: 800.553 .6847

fax: 703.605.6900

email: orders@ntis.fedworld.gov online ordering: http://www.ntis.gov/help/ordermet $\underline{\text { hods.aspx }}$

\section{CitATION}

Please cite as follows:

Stephens, T. (March 2013). Non-Cost Barriers to Consumer Adoption of New Light-Duty Vehicle Technologies. Transportation Energy Futures Series. Prepared for the U.S. Department of Energy by Argonne National Laboratory, Argonne, IL. DOE/GO-102013-3709. 47 pp. 


\section{REPORT CONTRIBUTORS AND ROLES}

Argonne National Laboratory

Thomas Stephens

Lead and primary author 


\section{ACKNOWLEDGMENTS}

We are grateful to colleagues who reviewed portions or the entirety of this report in draft form, including:

Jeff Alson, Senior Policy Advisor, Transportation and Climate Division, Office of Transportation and Air Quality, U.S. Environmental Protection Agency (EPA)

Susan Burke, Environmental Scientist, Transportation and Climate Division, Office of Transportation and Air Quality, EPA

Gloria Helfand, Environmental Protection Specialist, Assessment and Standards Division, Office of Transportation and Air Quality, EPA

Arthur Rypinski, Economist, Office of the Secretary, U.S. Department of Transportation

Dr. Tom Turrentine, Director, Plug-in Hybrid Electric Vehicle Research Center and Research Anthropologist, University of California Davis, Institute of Transportation Studies

Steve Zimmer, Executive Director, U.S. Council for Automotive Research

Participants in an initial Transportation Energy Futures scoping meeting in June 2010 representing the U.S. Department of Energy and national laboratories - assisted by formulating innovative and timely ideas to consider for the project. Steering Committee members and observers offered their thoughtful perspective on transportation analytic research needs as well as insightful comments on an initial Transportation Energy Futures work plan in a December 2010 meeting, and periodic teleconferences through the project.

Many analysts and managers at the U.S. Department of Energy played important roles in sponsoring this work and providing valuable guidance. From the Office of Energy Efficiency and Renewable Energy, Sam Baldwin and Carla Frisch provided leadership in conceptualizing the project. A core team of analysts collaborated closely with the national lab team throughout implementation of the project. These included:

Jacob Ward and Philip Patterson (now retired), Vehicle Technologies Office

Tien Nguyen and Fred Joseck, Fuel Cell Technologies Office

Zia Haq, Kristen Johnson, and Alicia Lindauer-Thompson, Bioenergy Technologies Office

The national lab project management team consisted of Austin Brown, Project Lead, and Laura Vimmerstedt, Project Manager (from the National Renewable Energy Laboratory); and Tom Stephens, Argonne Lead (from Argonne National Laboratory). Data analysts, life cycle assessment analysts, managers, contract administrators, administrative staff, and editors at both labs offered their dedication and support to this effort. 



\section{TABLe OF Contents}

List of Figures

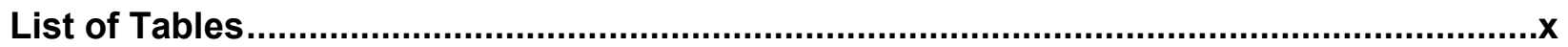

Acronyms

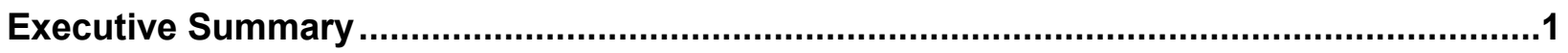

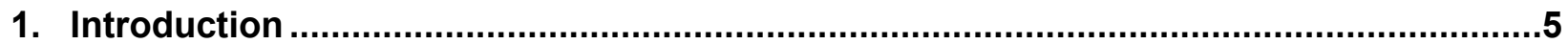

2. Types of Non-Cost Barriers to New Vehicle Technology Adoption...............................

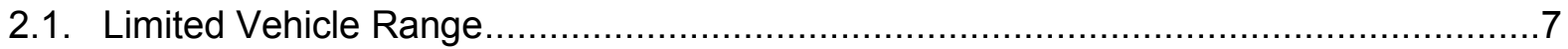

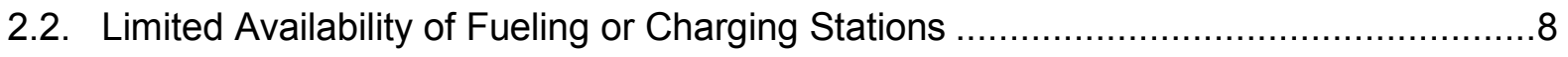

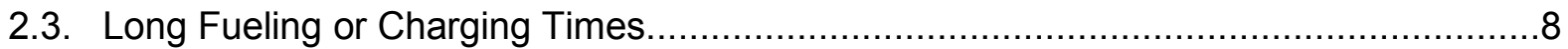

2.4. Limited Availability, Number, and Diversity of Models ...........................................

2.5. Unfamiliarity, Uncertainty, and/or Lack of Information About New Vehicle

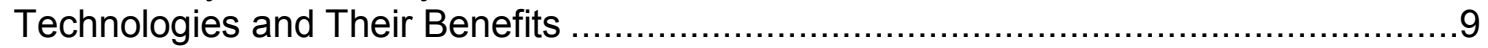

2.6. Consumer Predispositions toward Certain Vehicles or Perceptions about Differences in Their Performance, Safety, and Other Attributes..............................................

2.7. Regulations and Lack of Standardization/Codes .............................................. 10

3. Approaches to Quantifying and Ranking Non-Cost Barriers ....................................11

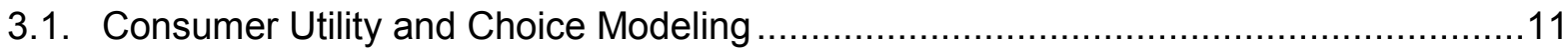

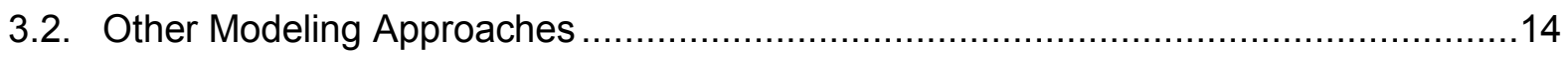

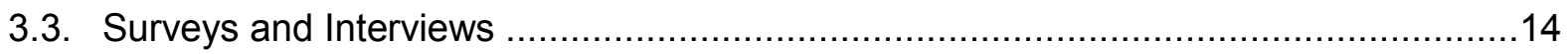

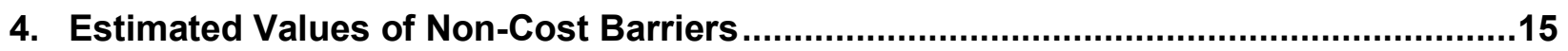

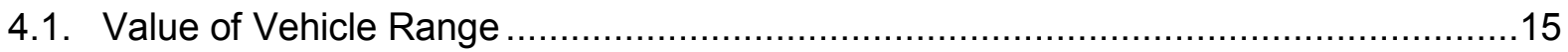

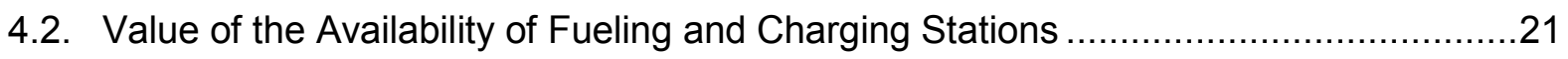

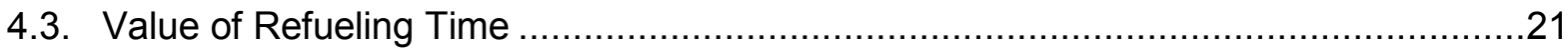

4.4. Combined Valuation of Vehicle Range, Fuel Availability, and Refueling Time ...........22

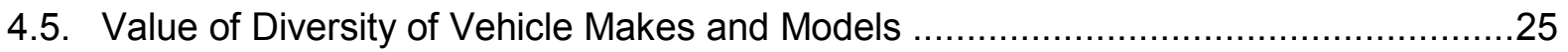

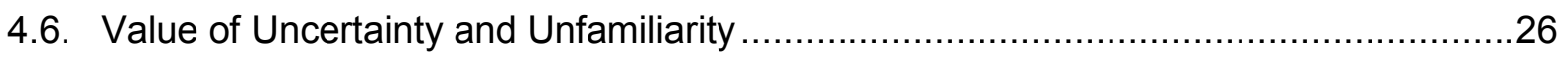

4.7. Consumer Predispositions and Perceived Differences between Vehicles...................28

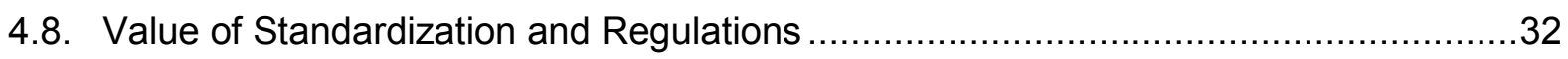

4.9. Observations on Methods for Quantifying Non-Cost Barriers..................................32

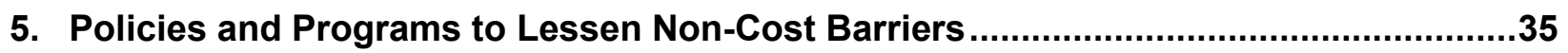

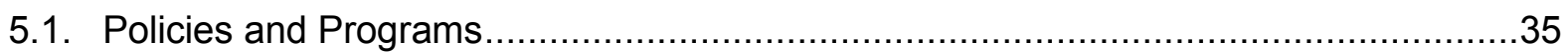

5.2. Effectiveness and Challenges of Policies and Programs in Addressing Non-Cost

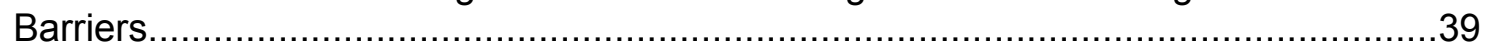

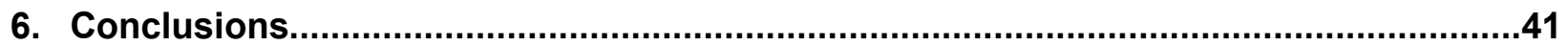

Appendix: Market Shares and Implied Value in Nested, Multinomial Logit Models ...........43

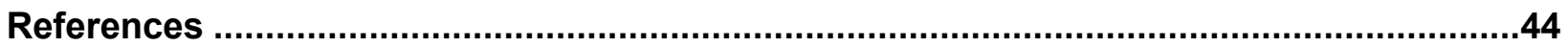




\section{LIST OF FIGURES}

Figure 4.1. Implied value (IV) and compensating variation (CV) .................................16

\section{LIST OF TABLES}

Table ES.1. Non-Cost Barriers Ranked by Severity and Possible Policy Effectiveness..............2

Table 4.1. Ranking of Barriers in Order of Severity 33

Table 6.1. Non-Cost Barriers Ranked by Severity and Possible Policy Effectiveness. 


\section{ACRONYMS}

$\begin{array}{ll}\text { AFDC } & \text { Alternative Fuels Data Center } \\ \text { BEV } & \text { battery electric vehicle } \\ \text { DOE } & \text { U.S. Department of Energy } \\ \text { EV } & \text { electric vehicle } \\ \text { FCV } & \text { fuel cell vehicle } \\ \text { FHWA } & \text { Federal Highway Administration } \\ \text { HEV } & \text { hybrid electric vehicle } \\ \text { MA }^{3} \text { T } & \text { Market Acceptance of Advanced Automotive Technologies (model) } \\ \text { mpg }_{\text {NHTS }}^{\text {mile(s) per gallon }} \\ \text { PHEV } & \text { National Household Travel Survey } \\ \text { R\&D } & \text { plug-in hybrid electric vehicle } \\ & \text { research and development }\end{array}$





\section{EXECUTIVE SUMMARY}

\section{Identifying Issues Beyond Vehicle Price}

The rate of adoption of new vehicle technologies and related reductions in petroleum use and greenhouse gas emissions rely on how rapidly technology innovations enter the fleet through new vehicle purchases. New technologies often increase vehicle price, which creates a barrier to consumer purchase, but other barriers to adoption are not due to increased purchase prices. For example, plug-in vehicles, dedicated alternative fuel vehicles, and other new technologies face non-cost barriers such as consumer unfamiliarity or requirements for drivers to adjust behavior. This report reviews recent research to help classify these non-cost barriers and determine federal government programs and actions with the greatest potential to overcome them.

Dealing with difficult-to-define non-cost barriers is a challenge to research and development (R\&D) program managers, automakers, policymakers, and others interested in the deployment of advanced vehicles. Future deployment of new passenger vehicle drivetrain technologies and alternative fuels in markets around the globe is difficult to foresee from previous experience with more traditional vehicle technology. Nevertheless, earlier consumer behavior studies can help identify major types of barriers and related factors, as well as provide insight into policy interventions with the greatest promise for lowering these barriers.

This report provides an accessible summary of methods for assessing non-cost barriers and findings of existing studies. Table ES.1 lists non-cost barriers, along with approximate magnitudes and most important driving factors. This information can be used to better understand barriers, evaluate their interactions with vehicle cost, assess potential adoption rates of new vehicle technologies, consider the possible implications of policy actions or changes in market conditions, and conduct more thorough cost/benefit analyses of potential policies.

\section{Non-Cost Barrier Severity and Solutions}

The non-cost barriers considered in this report are listed in Table ES.1 in order of severity, based on surveys, interviews, sales and economic data, and modeling from the studies reviewed. Also listed are the most important factors governing the severity of each barrier. Non-cost barriers were ranked according to the magnitude of severity and the potential effectiveness of policies available to address them. Each barrier was assigned an "effective cost," or order-of-magnitude approximate dollar value that would compensate for the barrier. Any barrier judged to be severe enough to discourage some consumers from purchasing a vehicle was assigned a value of $\$ 10,000$ as an upper estimate of the effective cost.

However, some consumers may be willing to pay a price premium; hence, this is indicated by a negative lower bound.

\section{Key Findings}

- Non-cost barriers can be significant enough to deter consumers from considering some types of advanced vehicles.

- Estimated effective costs of non-cost barriers calculated based on the results of surveys, sales and economic data, and modeling are highly uncertain.

- While some policies and programs are likely to be effective in reducing certain non-cost barriers, it is difficult to quantify potential policy impact using currently available information.

- To improve on existing estimates, consumer behavior and public attitude and perception studies would be needed as new vehicle technologies enter the market and the on-road vehicle stock. 
Transportation Energy Futures researchers considered the effectiveness of policies in reducing non-cost barriers and identified implementation challenges. Policies considered in this report include programs that:

- Provide potential consumers experience in driving vehicles

- Offer public outreach and information programs

- Include incentives for charging and fueling infrastructure development

- Establish technology standards.

Table ES.1. Non-Cost Barriers Ranked by Severity and Possible Policy Effectiveness

\begin{tabular}{|c|c|c|c|c|c|}
\hline Non-Cost Barrier & Effective Cost & Governing Factors & Possible Policies & $\begin{array}{l}\text { Potential Policy } \\
\text { Effectiveness }\end{array}$ & Policy Challenges \\
\hline \multirow{2}{*}{$\begin{array}{l}\text { Limited driving } \\
\text { range, limited } \\
\text { fueling and } \\
\text { charging stations, } \\
\text { long fueling and } \\
\text { charging times }\end{array}$} & \multirow[b]{2}{*}{$\$ 1,000$ to $\$ 10,000$} & \multirow{2}{*}{$\begin{array}{l}\text { Vehicle's range, } \\
\text { driver's mobility } \\
\text { needs, availability } \\
\text { of home charging } \\
\text { and fueling, } \\
\text { driver's value of } \\
\text { time, availability of } \\
\text { alternatives }\end{array}$} & $\begin{array}{l}\text { Provide incentives } \\
\text { for building more } \\
\text { stations }\end{array}$ & $\begin{array}{l}\text { Probably } \\
\text { effective, if many } \\
\text { stations are built }\end{array}$ & High cost \\
\hline & & & $\begin{array}{l}\text { Pilot programs } \\
\text { (e.g., test drive, } \\
\text { fleet, lease), } \\
\text { information }\end{array}$ & $\begin{array}{l}\text { Probably } \\
\text { somewhat } \\
\text { effective }\end{array}$ & $\begin{array}{l}\text { Tailoring policies } \\
\text { to driver mobility } \\
\text { needs }\end{array}$ \\
\hline $\begin{array}{l}\text { Unfamiliarity, } \\
\text { uncertainty } \\
\text { regarding benefits, } \\
\text { lack of awareness } \\
\text { or information }\end{array}$ & $\$ 100$ to $\$ 10,000$ & $\begin{array}{l}\text { Prevalence of new } \\
\text { technology, } \\
\text { preferences of } \\
\text { early adopters }\end{array}$ & $\begin{array}{l}\text { Labeling, } \\
\text { information, } \\
\text { outreach programs }\end{array}$ & Effective & $\begin{array}{l}\text { Tailoring policies } \\
\text { to early adopters, } \\
\text { sustaining long- } \\
\text { term policies }\end{array}$ \\
\hline $\begin{array}{l}\text { Perceived } \\
\text { differences in or } \\
\text { predispositions for } \\
\text { or against } \\
\text { advanced } \\
\text { technology } \\
\text { vehicles }\end{array}$ & $-\$ 1,000$ to $\$ 10,000$ & $\begin{array}{l}\text { Social and } \\
\text { behavioral factors }\end{array}$ & $\begin{array}{l}\text { Information, } \\
\text { outreach programs }\end{array}$ & $\begin{array}{l}\text { Probably } \\
\text { effective }\end{array}$ & $\begin{array}{l}\text { Tailoring policies } \\
\text { to early adopters, } \\
\text { sustaining long- } \\
\text { term policies }\end{array}$ \\
\hline $\begin{array}{l}\text { Lack of adequate } \\
\text { technology } \\
\text { standardization }\end{array}$ & Potentially $>\$ 1,000$ & $\begin{array}{l}\text { Maturity of new } \\
\text { technologies, } \\
\text { potential for } \\
\text { incompatibilities or } \\
\text { safety issues }\end{array}$ & $\begin{array}{l}\text { Testing, standards } \\
\text { development }\end{array}$ & Effective & $\begin{array}{l}\text { Complexity of } \\
\text { technologies and } \\
\text { future business } \\
\text { models, } \\
\text { sustaining testing } \\
\text { and } \\
\text { standardization } \\
\text { efforts }\end{array}$ \\
\hline $\begin{array}{l}\text { Limited availability } \\
\text { and diversity of } \\
\text { vehicle makes and } \\
\text { models }\end{array}$ & $\$ 100$ to $\$ 1,000$ & $\begin{array}{l}\text { Consumer } \\
\text { preferences, } \\
\text { modularization of } \\
\text { design and } \\
\text { manufacturing }\end{array}$ & $\begin{array}{l}\text { R\&D on } \\
\text { modularization }\end{array}$ & Limited & $\begin{array}{l}\text { Limited role for } \\
\text { public policy }\end{array}$ \\
\hline Regulations & Minor & $\begin{array}{l}\text { Requirements or } \\
\text { restrictions unique } \\
\text { to advanced } \\
\text { technology } \\
\text { vehicles }\end{array}$ & * & * & * \\
\hline
\end{tabular}

${ }^{*}$ Regulatory reforms were not considered due to the low magnitude of this barrier 
Because of the difficulty associated with judging potential policy effectiveness, greater weight was placed on the effective cost of each barrier in assigning relative rankings. Policies directed at reducing the costs or improving the performance of advanced technology vehicles were not assessed for this report.

Current data on consumer choices and use of new types of vehicles remain limited. Estimates of effective costs in Table ES.1 rely largely on surveys or stated preferences of consumers, not on actual purchasing behavior data. In the future, vehicle technologies, vehicle ownership and use patterns, and public attitudes might be different enough to change the relative importance of non-cost barriers and policy effectiveness.

As markets, consumer preferences, and driver use patterns for advanced technology vehicles develop, it will be important for policymakers and R\&D experts to discover what barriers prove most important and what measures are effective in overcoming them. Future work will also help better understand how factors that give rise to these barriers depend on consumer travel needs and preferences and on local conditions, including socioeconomic and demographic factors.

\section{A Framework for Future Research}

The successful deployment of advanced technology vehicles depends strongly on overcoming barriers posed by non-cost factors, as well as high purchase prices. While this report offers an initial characterization of non-cost barriers, much remains to be learned about consumer adoption of advanced technology vehicles, and it will be important to continue to study consumer behavior and public perception of vehicle technologies.

For the purpose of this report, effective costs were estimated only in terms of orders of magnitude, and policies were not quantified but were ranked relatively. No attempt was made to analyze the monetary costs and benefits of policies. While the ranking in the table suggests which barriers are most severe and which ones might be addressed by the policies considered, it is not a given that addressing the most severe barriers would provide the greatest benefit, that efforts to address them should be pursued at the expense of other non-cost issues, or that the values are in any way additive. It is also important to realize the limitations associated with attempting to assign a range of effective costs to these barriers. The range of effective costs is very broad, because barriers result from the impact different factors have on consumers with diverse travel needs and vehicle preferences.

Further work to better characterize these barriers will be important, particularly to better estimate the potential market shares of the full range of vehicle technologies in relation to a wide spectrum of consumers, preferences, and driving needs. Such work will make it possible to more effectively break down barriers and more accurately assess each vehicle's true potential for reductions in passenger vehicle-related energy use and greenhouse gas emissions. 



\section{INTRODUCTION}

Reductions in petroleum use by and greenhouse gas emissions from light-duty vehicles are possible through the deployment of new technologies that enable greater energy efficiency and the use of lowcarbon forms of energy. The level of reductions depends on how quickly and to what extent these technologies enter the fleet through new vehicle purchases, which depend on consumer preferences.

The focus of this report is on non-cost barriers associated with consumer purchasing behavior. Although auto manufacturers also face barriers in developing and new technology and bringing it to market, most of these barriers are cost-related. Since automakers are highly motivated to maximize profits, and profits are largely determined by sales of their products, barriers to consumer sales are of primary importance.

Non-cost barriers can prevent consumers from purchasing energy-efficient and emission-reducing lightduty vehicles. Advanced vehicle technologies that improve fuel economy may increase the vehicle's price, which presents a barrier to adoption even if savings in the cost of fuel over time offset the increased purchase price. However, other factors, some of which are independent of vehicle price or operating cost, are also important. These include barriers to adoption (vehicle purchase) due to:

- Consumers' unfamiliarity with new technologies

- Limited vehicle driving range and/or availability of fuel

- Perceived differences in the vehicle's safety, performance, or functionality

- $\quad$ Limited vehicle features and models

- Individual consumer bias or favoritism.

Rather than an exhaustive review of consumer choice models or consumer surveys, this report discusses selected sources that exemplify various methods and salient results. This report uses the ranges of values found in these sources and considers factors that give rise to barriers in order to estimate the approximate severity of non-cost issues.

Approaches used to quantify barriers in previous studies of consumer choice behavior and advanced vehicle adoption can be used to relate characteristics of non-cost barriers to the potential market size, sales forecast, or adoption rate of advanced technology vehicles. Methods that relate non-cost barriers to the sales of an advanced technology or its potential market size are reviewed and used to assign an approximate value to the severity of these barriers, as well as less quantitative literature on factors influencing vehicle purchases. This report builds upon two prior works by Helfand and Wolverton (2009), who reviewed barriers to consumer adoption of fuel efficient vehicles, including cost and non-cost barriers; and Greene's (2010) review of work estimating consumers' willingness to pay for increased fuel economy. Neither of these reviews attempted to quantify the non-cost barriers examined here.

Policies and programs designed to overcome these barriers are also discussed. Although the effectiveness of polices is very difficult to quantify, a relative ranking was performed based on empirical evidence from the literature. Non-cost barriers are listed in order of the magnitude of their potential effects on the rates of adoption or the market share of new technologies, and in order of feasibility of actions to mitigate the barriers. This is one of many possible rankings; it does not imply priorities for action, and is not based on a cost-benefit analysis.

The next section describes non-cost barriers and the factors that contribute to them. Section 3 discusses methods for assessing the magnitudes of these barriers. Section 4 provides results from selected studies that estimate barrier severity, and it suggests a ranking of barriers. Policies to lessen non-cost barriers are discussed in Section 5. In Section 6, barriers are ranked by their severity and a rough indication of the potential effectiveness of policies to reduce the barriers is provided. 
A more thorough prioritization scheme might include an analysis of the costs and benefits of policies and programs. The increased cost and the undervaluing of benefits of new technologies external to market decisions are not considered in this report. 


\section{Types Of Non-Cost BarRiers to New VehicLe TECHNOLOGY ADOPTION}

Non-cost barriers are factors that negatively affect the adoption rate of a new vehicle technology but that are not direct costs, such as the known and quantified purchase cost or the operations and maintenance costs. The perceived risk of higher operations and maintenance costs is considered a non-cost barrier. Not discussed here are barriers due to the increased cost of new technologies or barriers caused by undervaluing the benefits of new technologies that are external to market decisions.

Non-cost barriers to the adoption of new vehicle technologies include these:

- Limited vehicle range. This results in range anxiety, thereby limiting vehicle travel options and thus vehicle utility, especially if the fuel (or electricity) is not readily available.

- Limited availability of fueling or charging stations. This increases range anxiety.

- Long fueling or charging times. This is especially important if the vehicle range is limited or if fuel or electricity is not widely available.

- Limited availability/number/diversity of models. This inhibits purchasing a vehicle with a new technology even when it is desired because it's not available with other desired features.

- Lack of information on or unfamiliarity with new vehicles or their refueling systems. This creates uncertainty about future costs, benefits, reliability, convenience, and/or required adaptations. Contributing to this are (1) unreliable sources of information (e.g., car dealerships) that may filter information available to consumers or may be seen as suspect or unreliable sources by consumers, (2) uncertainty regarding future fuel prices, (3) uncertainty about the vehicle's lifetime, and (4) other factors.

- Less tangible factors influencing consumer vehicle choice behavior. These include perceived differences in performance, safety, or other attributes, as well as connotations or associations that result in a predisposition for or a dislike of certain vehicle types.

- Lack of standardization/codes. This creates uncertainty regarding the technology's compatibility with the available charging/refueling infrastructure and may lead to safety concerns.

- Regulations that may restrict operations. These are relevant for some alternative fuel vehicles. These regulations (e.g., tunnel restrictions) may restrict the places where vehicles can be driven.

These barriers act more directly on vehicle purchasers than on vehicle manufacturers or on fuel suppliers. Nevertheless, such barriers to consumer adoption of advanced technology vehicles do affect decisions by automakers and fuel suppliers, since decisions to invest in advanced vehicle manufacturing and fuel supply infrastructure are sensitive to consumer demand.

Many non-cost barriers are due to social or behavioral factors that are qualitative and difficult to quantify. However, to the extent possible, the effects of some of these factors on rates of adoption or on the potential market share of new technologies are assessed on the basis of the available literature and are included in the value assigned to non-cost barrier severity.

\subsection{Limited Vehicle Range}

Some advanced technology vehicles, such as battery electric vehicles (BEVs) and vehicles that use only alternative fuels (e.g., hydrogen or compressed natural gas) may have a shorter driving range than conventional vehicles. Depending on the availability of charging or fueling stations, drivers may be concerned about the possibility of running out of electricity or fuel. This is commonly called "range 
anxiety." Limited range vehicles may not be useable for longer trips if charging or fueling stations are not available. If drivers feel that they cannot use a vehicle for some of their trips, this represents a significant barrier to purchasing such a vehicle.

\subsection{Limited Availability of Fueling or Charging Stations}

The inability to conveniently find fuel for a dedicated alternative fuel vehicle is a significant barrier to purchasing such vehicles. For range-limited vehicles, such as alternative fuel vehicles or BEVs, if the alternative fuel or electricity for charging stations is not widely available, the range limitation barrier is more severe. Addressing this barrier requires the installation of enough charging/fueling stations, and it requires the generation/production system and distribution system to supply stations. Installation of such infrastructure is hampered by the uncertainty of future demand for charging/fueling stations, which increases the risk associated with the investment required. Therefore, consumer adoption of dedicated alternative fuel vehicles or BEVs is coupled with the development of a charging/fueling infrastructure and with expectations about the future infrastructure.

\subsection{Long Fueling or Charging Times}

An issue related to the two barriers above is the time required for charging or fueling, if this time is significantly longer than typical fueling times for gasoline-powered vehicles. Some trips have a very high value to drivers, such as trips in emergency situations, and even if these trips are rare, the loss of utility that could result from the possibility of not being able to use a vehicle on demand may be a significant factor. Even for more routine trips, the value of the time spent charging or fueling a vehicle may be a significant factor, as may be the perceived inconvenience of waiting for more than a few minutes when charging or fueling.

These first three non-cost barriers are coupled and are difficult to assess individually, since they are closely coupled. The effectiveness of measures to address these barriers depends on how vehicles are used and how drivers adapt to these limitations. Drivers can adapt their vehicle use to accommodate a limited range or long refueling times, especially if the vehicle is a second or third vehicle in the household. However, if the market for such vehicles is limited to such households, this presents a barrier to widespread adoption. In 2009, about $34 \%$ of U.S. households owned only one vehicle [Federal Highway Administration (FHWA) undated], and this fraction had been fairly stable over the last 20 years. The fraction owning three or more vehicles increased from 18\% in 2000 (Davis et al. 2010, Table 8.4) to 23\% in 2009 (FHWA undated). Of all households buying new vehicles, only about 7\% are one-vehicle households, based on the 2001 National Household Travel Survey (NHTS) (FHWA 2005). Drivers who make long trips may be reluctant to adapt by renting or borrowing a vehicle with the required range, sharing a ride, or using other travel modes. These adaptations have costs, in money, time, or convenience. Estimates of these costs are reviewed and used to assess the severity of this barrier.

\subsection{Limited Availability, Number, and Diversity of Models}

As new vehicle technologies are introduced, they are often offered in limited makes or models. Since consumers desiring the utility offered by the new technology may not find it bundled with other desired vehicle features, they may choose a vehicle without the technology. The diversity of vehicles in which a technology is offered has value, so a lack of diversity represents a barrier (Greene 2001).

Vehicle manufacturers can offer new technologies in more makes and models, but they face significant cost barriers to scaling up across their product line and uncertainty in the market demand for vehicles with new technologies. Consumer acceptance of vehicles with new technologies is the key to manufacturers when they are deciding how widely to include the technology across their product line. 


\subsection{Unfamiliarity, Uncertainty, and/or Lack of Information About New Vehicle Technologies and Their Benefits}

New vehicle technologies are often unfamiliar to many consumers. Early adopters and technology enthusiasts may follow technologies as they are developed and commercialized, but they represent only a small fraction of potential consumers. Consumers who learn about new technologies only from advertising or in the automobile showroom may not have enough information to assess the potential value of these technologies. Consumers who are considering purchasing a vehicle often think that ads or salespeople are biased sources of information, and, indeed, automotive sales people are sometimes unable to provide complete and accurate information on new vehicle technologies (Melendez 2006). Consumers faced with choices about unfamiliar features may question not only the value of the feature but also its potential impacts on vehicle reliability and maintenance costs.

Even for consumers willing to consider a vehicle with a new technology, any uncertainty regarding its value, performance, or other characteristics can be an incentive for them to delay purchasing it, especially if they anticipate that they could learn from the experiences of others. Although consumers shopping for a fuel-efficient vehicle can see the fuel economy values and estimated annual fuel savings on the "window stickers" of new cars, they may be uncertain of the fuel savings they would actually realize when driving a given vehicle. Also, many new vehicle technologies require specialized components, such as batteries and fuel cells, or new assembly and repair and maintenance methods required for some lightweight materials, such as aluminum or fiber-reinforced composites. Consumers may be hesitant to buy new vehicles unless they are confident that parts and maintenance are readily available at costs comparable to those they are accustomed to for conventional vehicles. Higher maintenance costs represent a cost barrier. Of interest here is the uncertainty regarding future operating costs, which can be a barrier, even if such costs, especially fuel costs, are likely to be lower than those of a conventional vehicle.

Although early adopters are often willing to purchase new products before their value and reliability are established, most customers who are making major purchases, such as vehicle purchases, are more conservative. Consumers can get more familiar with the vehicles by reviewing multiple media sources, by seeing new vehicles on the road, through interactions with other consumers, and by test-driving or renting new vehicles.

Empirical research on how people make decisions under uncertainty has shown that people's degree of risk aversion strongly affects decisions, and that the effect depends on the context (e.g., whether the risk is presented as an uncertain gain or an uncertain loss). Greene (2011) reviewed risk averse behavior in the context of energy efficiency and technology choices. When future benefits from technology are uncertain and may result in a net loss, many people assign greater weight to potential losses than potential gains, and the bias against losses is greater the greater the uncertainty is. Other factors can also be important, such as whether the uncertainty is temporary (additional information that will reduce uncertainty is expected) and whether the decision is irreversible.

\subsection{Consumer Predispositions toward Certain Vehicles or Perceptions about Differences in Their Performance, Safety, and Other Attributes}

New technologies may be used in vehicles to increase fuel economy, performance, and other attributes. Typically there is a trade-off between gains in fuel economy and performance (Bandivadekar, et al. 2008). Some consumers associate high fuel economy with poor performance, or with unreliability, or with the compromising of other desirable attributes. Other consumers associate high fuel economy with small vehicle size and a lower level of crash safety (Greene 2010). These associations might be weakening with time, however, since more current vehicle models have better acceleration, a similar or greater amount of interior space, and higher fuel economy than previous years' models. Some consumers have associated 
diesel engines with unreliability and foul-smelling emissions, although these associations also may be weakening with advances such as the use of ultralow-sulfur diesel fuel, increasing regulation of diesel emissions, and evidence of the reliability of diesel engines in light trucks and cars.

Personal vehicles are important to owners as symbols of status, personality, and other qualitative values. Vehicles with new technology are often associated with these values, and if such an association has negative connotations (i.e., if consumers are predisposed against certain types of vehicle or technologies), this can be a significant barrier to vehicle sales. On the other hand, if new technologies have value to some consumers (e.g., if consumers prefer charging at home over refueling at a gas station, or if new technologies have positive connotations), then these consumers may have a preference for or be predisposed to purchase such vehicles. In this case, the "barrier" is negative; that is, such consumers would be willing to pay more for the advanced technology vehicle than for a comparable conventional vehicle, and the effective cost is actually a premium.

\subsection{Regulations and Lack of Standardization/Codes}

Regulations restricting vehicles with compressed flammable gases on board may limit the use of some alternative fuel vehicles on some routes. Regulations can place constraints on the installation of charging and fueling stations. However these regulations, if well-designed, do not represent barriers to technology adoption if they help prevent serious accidents or poor performance of new technologies. Avoiding such problems is essential in gaining public acceptance of new technologies.

Well-designed standards are necessary to promote the adoption of safe, compatible, and better-performing technology. For example, uniform configurations for electrical connectors and protocols for payment are needed to avoid installing charging stations that are unusable by some plug-in vehicle drivers. Similarly, well-established specifications for alternative fuels and the standardization of other new vehicle technologies can make the technologies easier to use and decrease the risk to consumers of buying something that may soon become obsolete. Well-designed standards also simplify making new technologies safe for consumers. For example, safety standards for charging equipment support the design of connectors that can transmit several kilowatts of electric power with a minimal shock hazard to users, under all expected weather conditions. Many of these standards and specifications are rapidly evolving as the technology continues to develop. While many standards are transparent to end users and have no direct effect on vehicle purchase decisions, a lack of effective standardization can lead to poor performance, safety problems, or incompatibilities that can become large barriers to adoption of new technologies. 


\section{Approaches to QuANTIfying ANd Ranking NON-COST BARRIERS}

Approaches to characterizing barriers to adoption of new technologies by consumers include the modeling of consumer utility and vehicle choice, other modeling approaches including system dynamics and agent-based-modeling, surveys and interviews, and the analysis of data from instrumented vehicles. These methods are often used together (e.g., results from surveys can be used to estimate parameters in models). Each of these approaches is briefly discussed in the text that follows. In Section 4, representative studies of each type are reviewed, and from the results of these studies, approximate magnitudes or measures of severity of non-cost barriers are estimated. In some cases, a quantitative value in dollars can be estimated, representing the equivalent cost of a barrier, or the amount a consumer would have to be compensated for accepting a vehicle with this barrier. For several barriers, the studies reviewed here indicate how the severity of the barrier depends on the most important factors characterizing the barrier. Also noted are limitations of these approaches to quantifying certain non-cost barriers.

\subsection{Consumer Utility and Choice Modeling}

Barriers to vehicle purchase by consumers can be quantified if the effect of the barrier on the consumer's perception of the utility of the vehicle can be estimated. This is an important method that provides the basis for the quantification of several barriers in this report. It allows monetary values to be assigned to some non-cost barriers and can be used to quantify the dependence of these values on factors that govern the importance of these barriers. The modeling of consumer utility is done in models of consumer vehicle choice that relate a consumer's preferences for different vehicle attributes to the probability that the consumer will purchase a vehicle with those given attributes. By using vehicle choice models, barriers to vehicle adoption can be quantified in terms of their impact on market share, and the magnitude of barriers can be related to attributes of vehicles and consumers and other relevant factors. Vehicle choice models usually take the form of discrete choice models, in which probabilities of consumers purchasing specific vehicle types are estimated. Discrete choice models can take several forms, including several types of logit models (Train 2009). In these models, vehicle attributes are represented by parameters, and consumer choice probabilities are modeled by using functions that relate the utility of vehicle attributes to their parameter values. Heterogeneous populations can be modeled by using different functions for different consumer segments or by allowing the utility functions to depend on consumer attributes. For example, the utility of cargo space to a given consumer may be represented by a function of the quantity of cargo space in units of volume. The probability of a consumer choosing a vehicle with a given amount of cargo space depends on the marginal utility the consumer derives from cargo space (the change in utility with respect to change in cargo space). In these models, one attribute that is nearly always included is the vehicle purchase price, and the marginal utility of the price in dollars is the marginal utility of one dollar. Thus, marginal utilities can be used to monetize consumer values of vehicle attributes.

Parameters in utility functions are estimated on the basis of data from consumer preference surveys or sales records and observed or estimated price differences between vehicles having different quantities or values of various attributes. Greene (2001) provides a good discussion of utility functions as used in discrete vehicle choice models and explains utility parameters in a nested multinomial logit model he developed. For estimating parameters in utility functions for attributes of vehicles that have not been commercialized and for which there are no sales data, survey data (stated preference data) can be used. Surveys can be designed to elicit responses that indicate how much consumers value different attributes by recording their stated willingness to pay for certain quantities of various attributes in hypothetical vehicles or by their preferences when presented with choices of two or more hypothetical vehicles. Consumer preferences can be quantified from properly designed survey data in terms of willingness to pay for certain vehicle characteristics or values of quantifiable attributes, such as fuel economy, range, 
etc. Willingness to pay for attributes such as vehicle range, refueling time, fuel availability, etc. are useful measures of the barriers to vehicles that have shortcomings in these attributes.

In order to relate consumers' preferences to their probability of purchasing a given vehicle, a vehicle choice model must be formulated, and parameters must be estimated for a utility function. Once utility functions are estimated in terms of vehicle attributes and other factors, these can be used to provide estimates of implied value. (In some models, the other factors include consumer demographic or other characteristics and economic factors.) Of course, utility depends on both cost-related and non-cost factors, but such models are useful for quantifying the importance of the non-cost factors that are included in the model. The implied value for a vehicle attribute is the willingness to pay (in terms of increased purchase price) for a one-unit change in the quantity of the attribute. This is given by the ratio of marginal utility for the attribute to the marginal utility of purchase price. For example, the utility of vehicle $i$ (among $N$ available choices) having $M$ different attributes $X_{i j}$, may be represented as

$$
U_{i}=b_{1} X_{i 1}+b_{2} X_{i 2}+\cdots+b_{M} X_{i M}+\varepsilon_{i}
$$

where

$$
\begin{aligned}
& U_{i} \text { is the utility of vehicle choice } i \\
& X_{i j} \text { is the value of attribute } j \text { for vehicle choice } i \\
& \varepsilon_{i} \quad \text { is the error term (different for each choice } i \text { ) }
\end{aligned}
$$

Often, more general functions than just the linear form shown here are used (as discussed in the text that follows); however, in general, the higher a given vehicle's utility is, the more desirable the vehicle is relative to other available vehicles.

From a utility function such as Equation 1, implied values of vehicle attributes can be defined. If attribute 1 is the vehicle purchase price in dollars (i.e., the price of vehicle $i$ is $X_{i 1}$ ), then coefficient $b_{1}$ is the marginal utility of paying one dollar, and the implied value, $I V_{i j}$, of a unit of attribute $j$ in vehicle $i$ is given by the ratio of marginal utilities:

$$
I V_{i j}=-\frac{\frac{\partial U}{\partial X_{i j}}}{\frac{\partial U}{\partial X_{i 1}}}=-\frac{1}{b_{1}}\left(\frac{\partial U}{\partial X_{i j}}\right)
$$

The implied value of attribute $X_{i j}$ given by Equation 2 is simply the ratio of the change in utility from a one-unit change in $X_{i j}$ to the change in utility from a one-dollar change in the purchase price, or the value of one unit of the attribute in dollars. The utility functions that are usually chosen are those that are linear in the coefficients $b_{j}$, and these coefficients represent the marginal utility of attribute $j$. For linear utility functions, the implied value of a unit of attribute $j$ is then given by the ratio of the coefficient for that attribute to the coefficient for vehicle price. For example, if attribute 2 is fuel economy in miles per gallon (mpg), the implied value of a $1 \mathrm{mpg}$ increase in fuel economy is given by the ratio $-b_{2} / b_{1}$. (The ratio of $b_{2}$ to $b_{1}$ is negative since the marginal utility of paying the purchase price is negative, whereas the marginal utility of increased gas mileage is positive for a consumer who values fuel cost savings, so the implied value is positive.)

The estimation of the coefficient on vehicle price, $b_{1}$, is therefore important, since implied values depend on this coefficient. Methods used to estimate coefficients depend on the available data and on assumptions about correlations between variables, distributions of errors, functional forms assumed, and other details (Train 2009). In the case of a multinomial logit choice model, the coefficient for vehicle 
price can be related to the price, the market share, and the elasticity of demand. In this case, the coefficient on price is given in Train (2009, pp. 57-59) and Greene (2001):

$$
b_{1}=\frac{\frac{P_{j} \partial s_{j}}{s_{j} \partial P_{j}}}{P_{j}\left(1-s_{j}\right)}
$$

where

$$
\begin{array}{ll}
P_{j} & \text { is the price of vehicle } j \\
s_{j} & \text { is the market share of vehicle } j \\
\frac{P_{j} \partial s_{j}}{s_{j} \partial P_{j}} & \text { is the price elasticity of demand of vehicle } j
\end{array}
$$

Note that the elasticity is not constant but depends on market share. However, the elasticity at a given market share can be estimated from sales data for vehicles currently on the market, allowing the coefficient $b_{1}$ to be estimated. The overall price elasticity of demand for automobiles is close to -1.0 (Kleit 1990); however, the price elasticity of demand for vehicles within a market segment (e.g., midsize sedans) is larger in magnitude (more negative). One approach to modeling utility and consumer choice with segmentation of vehicles into classes is the nested multinomial logit model. Such models allow more general patterns of elasticities of substitution between vehicles within a defined class and between classes. In this case, Equation 3 must be generalized, as discussed further in the Appendix and in the examples that follow, drawing from results of nested multinomial logit vehicle choice models.

This methodology can be used to estimate consumer value or at least some quantitative measure of the importance of vehicle attributes (e.g., range and other factors, including consumer preferences). The use of implied values (as described previously) and other metrics in the context of consumer utility and choice models is reviewed in text that follows later. Estimates of consumer values for different vehicle attributes, including vehicle range (Section 4.1), limited availability of fueling and charging stations (Section 4.2), and fueling/recharging time (Section 4.3), are discussed in turn, as are methods that consider their combined effects (Section 4.4). The implied value of model diversity and availability is discussed in Section 4.5. The use of utility to assess the impact of uncertainty is discussed in Section 4.6, and the use of vehicle choice modeling to assess consumer predispositions and attitudes is discussed in Section 4.7. The limitations of this approach to assessing barriers resulting from a lack of standards are briefly discussed in Section 4.8. Note that there are theoretical difficulties and practical limitations of discrete choice models, as discussed in Train (2009) and Cherchi (2009). For example, many discrete choice models assume that vehicle prices are exogenous; that is, the prices are input parameters assumed to be independent of consumer choices and resulting market shares. This may not be the case if vehicle prices depend on the volume of vehicles produced (return to scale or decrease in cost with increasing scale of production). Also, vehicle prices may be correlated with vehicle attributes that are not included in the model (attributes unobserved by the analyst). If vehicles having unobserved attributes that are desired by consumers cost more for vehicle manufacturers to produce, there will be a positive correlation between the presence of these attributes and vehicle price. If this correlation is neglected when model parameters are estimated, then the price coefficient will be biased downward, since the probability of purchasing vehicles having the unobserved attributes will be higher than would have been the case if higher prices were not correlated with unobserved attributes. Approaches to deal with price endogeneity and correlations with unobserved variables are discussed in Train (2009, chapter 13). These methods require additional data or assumptions and are not always used. In any case, values estimated from these models can be highly uncertain or biased, and it is often difficult to know the degree of uncertainty or bias. 
In addition to methodological issues, a lack of sufficient sales data for advanced vehicles can make estimates of consumer utility for the attributes of these vehicles unreliable. Parameters describing consumer preferences for attributes of vehicles that are not on the market must be estimated from stated preferences from surveys or from economic theory and can be highly uncertain and essentially impossible to validate. However, these models provide a useful framework for describing the dependence of consumer utility and preferences on important driving factors in a way that is consistent with historical consumer behavior and economics, given what is known about consumers and advanced vehicles. Although implied value estimates are highly uncertain, it is useful to gauge the order of magnitude and the dependence on driving factors.

\subsection{Other Modeling Approaches}

Agent-based modeling, in which individuals can be represented explicitly and are allowed to interact with each other and with their environment, has been used to model populations of drivers and of vehicle purchasers. One example is reviewed in Section 4.4. System dynamics modeling is another approach; it follows variables such as vehicle use, vehicle purchasing, and other related factors over time. Quantities are modeled by using differential equations and assumptions about initial and boundary conditions. A systems dynamics model (which includes a vehicle choice model) is reviewed in Section 4.4.

\subsection{Surveys and Interviews}

Not all non-cost barriers can be represented in consumer choice models. Also, as noted, representing a barrier with a parameter in a model is not useful if no data are available to enable its estimation. Surveys can be used to gauge potential markets for new vehicles, but it is difficult to assess how accurately the stated preferences reflect actual behavior. Interviews can reveal more about consumer attitudes, perceptions, and motivations for vehicle purchases. Results of a few of these studies are discussed in Section 4. 


\section{Estimated VAlues of Non-Cost BaRRIERS}

Examples of estimated values for non-cost barriers are derived from work reviewed here. Several of these estimates are derived from vehicles choice models, as described previously, but some examples from other methods are also included. It is possible to derive separate estimates for the values for vehicle range, fueling and charging availability, and fueling and charging time, as shown in the following sections. As explained in Section 4.4, it is useful to consider the barriers from vehicle range, fueling and charging availabilities and times in combination. The quantification of other barriers (including a lack of diversity in models and makes, uncertainty of benefits, consumer predispositions, and a lack of technology standards and appropriate regulations) is discussed in subsequent sections.

\subsection{Value of Vehicle Range}

Several authors have developed vehicle choice models that include vehicle range as a variable for all vehicle types. From these models, an implied value of vehicle range can be derived. Some examples are discussed here.

Collantes (2010) gives an example of a nonlinear dependence of consumer utility on range, using the model of Brownstone et al. (2000), which uses a quadratic function to represent the value of range, with the utility expressed as:

$$
U=b_{1} \frac{\text { price }}{\ln (\text { income })}+b_{2} \text { fuel cost }+b_{3} \text { range }+b_{4} \text { range } e^{2}+\cdots+\varepsilon
$$

The implied value, as given by Equation 2, is then

$$
I V_{i j}=-\left[\frac{b_{3}+2 b_{4} \text { range }}{b_{1}}\right] \ln (\text { income })
$$

The implied value of vehicle range depends on consumer income as well as the range of the vehicle. In other words, given a vehicle with a certain range, a consumer making a given income would, on average, be willing to pay the value given by Equation 5 for a unit increase in range. Using the coefficients estimated by Brownstone et al. (2000), Collantes estimated the implied value by using this expression. This is plotted in Figure 4.1 for two values of annual income. The data used by Brownstone et al. (2000) included both sales records obtained from 607 households who had purchased vehicles between mid-1993 and late 1994 as well as survey responses collected from 4,747 households in 1993.

A similar measure of the value of an attribute is the compensating variation, defined as the increment in vehicle price that compensates for a difference in some vehicle attribute. In comparing two vehicle choices that are identical except in price and in one other attribute, $X_{2}$, the compensating variation is the increment in price that makes the perceived utility of the two vehicles the same; that is, for two vehicles $(j=1$ or 2$)$, the compensating variation, $C V$, is given by

$$
U_{1}=b_{1} \text { price }+b_{2} X_{2}=b_{1}(\text { price }+C V)+b_{2}\left(X_{2}+\Delta X\right)
$$

So $C V$ gives the difference in purchase price that would make a consumer indifferent to a change of $\Delta X$ in attribute 2 ; that is, a consumer should be equally willing to pay the amount price $+C V$ for a vehicle with attribute $X_{2}+\Delta X$ or to pay the amount price for a vehicle with attribute $X_{2}$. For utility functions that are 
linear in attribute $X_{2}$, the compensating variation is the same as the implied value, given by the ratio of marginal utilities as described above (see Equation 2), but in general, the compensating value is not the same as the implied value. Instead of a marginal value, the CV gives an increment in vehicle price equivalent to the value of a finite increment in a particular vehicle attribute.

For the utility function in Equation 3, the compensating variation for a change in range from a value of range $_{1}$ to range $e_{2}$ is then

$$
C V=\left[\frac{b_{3}}{b_{1}}\left(\text { range }_{1}\right)\left(1-\frac{\text { range }_{2}}{\text { range }_{1}}\right)+\frac{b_{4}}{b_{1}}\left(\text { range }_{1}\right)^{2}\left(1-\frac{\text { range }_{2}{ }^{2}}{\text { range }_{1}^{2}}\right)\right] \ln (\text { income })
$$

This is plotted in Figure 4.1 for the same two values of annual income. Note the $y$-axis in Figure 1 is the value of an increase of 100 miles in the vehicle range over the value plotted on the $x$-axis (i.e., for a given range $x$, what is the value of an increase of 100 miles in that range?). For example, the compensating variation, $C V$, for increasing vehicle range from 300 to 400 miles for an average consumer with an annual income of $\$ 40,000 / \mathrm{yr}$ is just under $\$ 8,000$, and the implied value, $I V$, is about $\$ 10,000$. The two measures show the same dependence on vehicle range but give slightly different values. Both the implied value and compensating variation estimated would imply that on average, consumers would pay several thousand dollars to increase the range of a vehicle from 300 to 400 miles, but they would not be willing to pay as much for an increase from 350 to 450 miles.

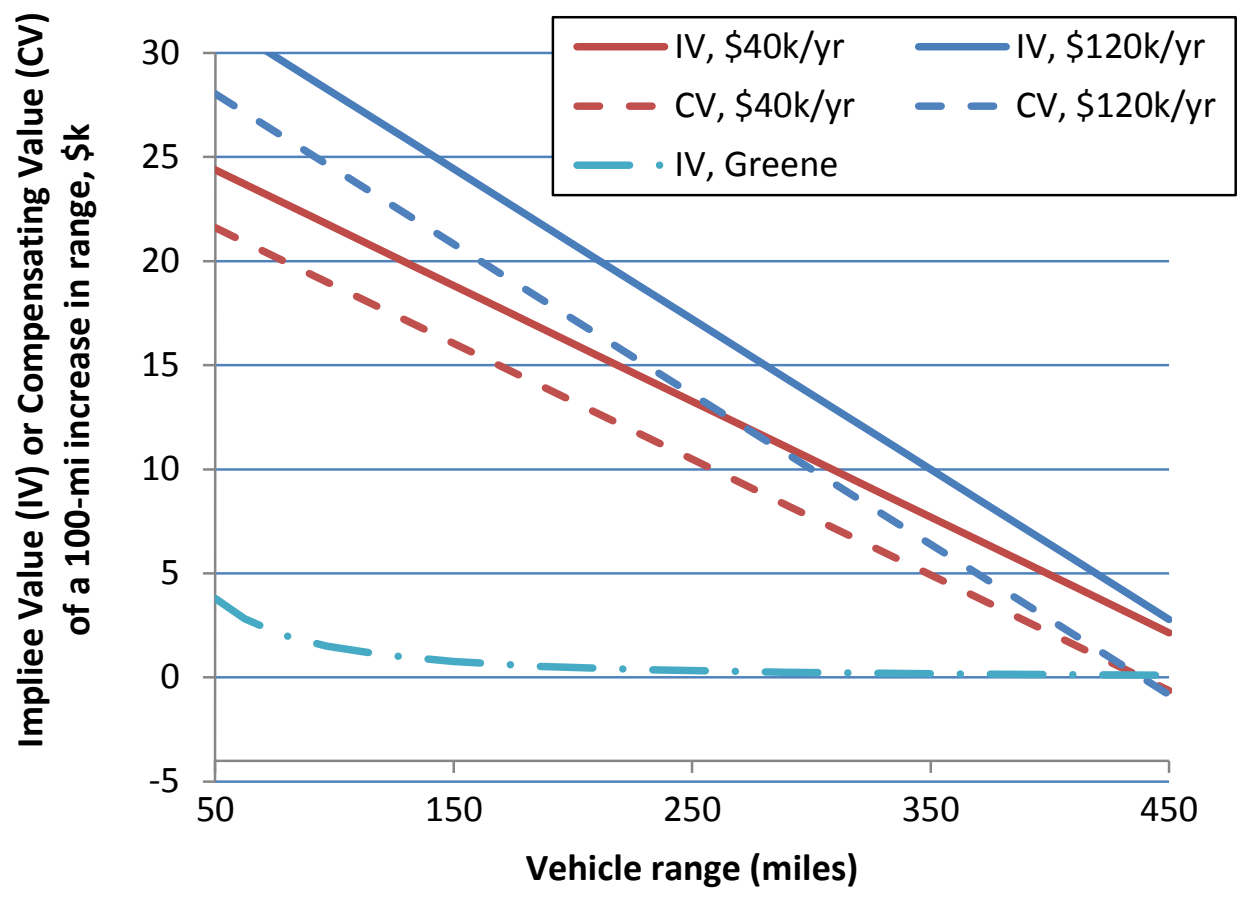

Figure 4.1. Implied value (IV) and Compensating Variation (CV)

Estimated by Collantes (2010) for an increase in vehicle range of 100 miles, plotted as a function of the nominal vehicle range (prior to the increase), for vehicle purchasers with annual incomes of $\$ 40,000$ and $\$ 120,000$. 
An alternate choice for representing the dependence of utility on vehicle range is to assume that utility is proportional to the reciprocal of range. The motivation for this choice comes from considering the value of travel time. For a given value of time, since the time spent refueling is inversely proportional to the average distance driven between refueling, the value of range is given in Greene (2001) as:

$$
V=\frac{1}{R} \sum_{i=1}^{N} \frac{w H M_{i}}{(1+r)^{i}}=k\left(\frac{1}{R}\right)
$$

where

$w \quad$ is the value of travel time, $\$ / \mathrm{h}$

$H \quad$ is the time required for refueling (searching for a station, waiting in line, refilling, and paying)

$M_{i} \quad$ is the miles driven in year $i$

$r \quad$ is the discount rate

$k \quad$ is defined in Equation (8) and units \$mi (i.e., the product of \$ and mi)

Greene (2001) estimated the approximate value of the coefficient $k$ for a vehicle with an effective range, $R$, of 300 miles and an on-road fuel economy of $25 \mathrm{mpg}$ as being $-285,000 \$ \mathrm{mi}$, using reasonable assumptions for the value of time, refueling time, and annual miles driven. This would imply that the value of increasing the vehicle range from 300 to $400 \mathrm{mi}$ would be slightly over $\$ 200$ - far less than the values ranging in thousands of dollars as estimated by Collantes. The implied value given by Equation 8 is plotted on Figure 4.1 to allow a comparison with the values given by Equations 5 and 7 . With a reciprocal range dependence, the value estimated from Equation 8 is much higher for vehicles having a more severely limited range. For example, the coefficient estimated in Greene (2001) would imply a value of $\$ 1,900$ for increasing the vehicle range from 50 to 75 miles. The large difference between the values estimated by Collantes and by Greene is not surprising considering the very different approaches they used. Collantes' estimate was based on the model of Brownstone et al. (2000), who estimated parameters in their model from survey results and sales data. Greene estimated the range coefficient in his model by considering the value of time and using estimates for this from economics literature. The discrepancy points out the difficulty of estimating a unique dollar value for vehicle range.

Hidrue et al. (2010) conducted a survey in which respondents were asked to choose between their preferred gasoline vehicle and two BEV versions of it. The preferred gasoline vehicle was specified based on the type of vehicle that the respondents said they were most likely to purchase next. The BEVs varied in attributes and price. From the survey responses, they estimated respondents' willingness to pay for five BEV attributes: driving range, fuel savings, charging time, pollution reduction, and performance. Respondents were asked to consider BEVs with driving ranges from 75 to 300 miles. Respondents were willing to pay from $\$ 35$ to $\$ 75$ for a mile of additional range, with the incremental willingness to pay per mile decreasing with increasing range: $\$ 75 /$ mile to increase from 75 to 150 miles, $\$ 73 /$ mile to go from 150 to 200 miles, and $\$ 35 /$ mile to go from 200 to 300 miles. This is comparable in magnitude to the range of values obtained from using the coefficient estimated by Greene (2001) for a limited range vehicle ( $\$ 80 /$ mile to go from 50 to 75 miles).

Santini and Vyas (2005) developed a vehicle choice model that was based on survey data in Tompkins et al. (1998) and estimated the coefficient of reciprocal range. They arrived at a value similar to that of Greene (2001) mentioned previously. However, they derived two estimates: one for the majority of the passenger vehicle market, and one for early adopters (i.e., consumers who are more apt to purchase vehicles with new technologies or functionalities). Their coefficient for the early adopter segment was a factor of 10 lower. This indicates the importance of market segmentation (that is, different consumers 
value attributes such as vehicle range very differently, especially with regard to vehicles with capabilities that are significantly different from those of mainstream vehicles). It also indicates the limitations associated with trying to assign a single dollar value to a vehicle range or its reciprocal.

The value of range for vehicles with a very limited range (e.g., less than 100 miles) can vary widely between consumers who have different driving needs and for whom the availability of other vehicles or travel modes differ.

Since the distance that passenger vehicles are driven each trip or each day varies widely between days and between drivers, it is not sufficient to examine average driving distances when considering whether a limited-range vehicle would meet drivers' range requirements. Lin and Greene (2011) examined the distribution of daily driving distances as estimated from the 2001 NHTS (FHWA 2005) and estimated the probability, $P_{a}$, that the daily driving distance would exceed the range of vehicles having effective ranges of 100, 150, and 200 miles. They fitted the daily driving distance distributions of 3,755 new car drivers in the NHTS records to gamma distributions and estimated the probability $P_{a}$ for each driver. From this, they estimated the fraction of drivers whose daily driving distance was longer than a given vehicle range for some number of days per year. For a $P_{a}$ of 0.1 (vehicle range exceeded on $10 \%$ of days), this fraction of drivers was about $50 \%$ for a 100 -mile range, about $20 \%$ for a 150 -mile range, and less than $10 \%$ for a 200-mile range. In more recent work, Lin et al. (2012) analyzed global positioning system travel data and validated the use of gamma distributions to describe distributions of daily driving distances.

Lin and Greene (2011) suggested a method to assign an approximate value to range by assuming a cost of $\$ 15$ for each day a vehicle had insufficient range. This value was taken to be intermediate between zero and the cost of a rental car (with sufficient range). From their statistics just described, they estimated a willingness to pay for sufficient range, and they found that the amount was broadly distributed, ranging from near zero to several thousand dollars. It can therefore be seen that assigning a single value to range can be misleading.

Of greater interest would be to examine how distributions of driving needs and assumptions about the utility of having a sufficient vehicle range affect the future adoption of range-limited vehicles by consumers. To examine the effect that vehicle range has on the likely size of the market for range-limited vehicles - specifically BEVs - Lin and Greene used a vehicle choice model they developed, the Market Acceptance of Advanced Automotive Technologies $\left(\mathrm{MA}^{3} \mathrm{~T}\right)$ model (Lin and Greene 2010a, 2011) to estimate future market shares of BEVs. In the $\mathrm{MA}^{3} \mathrm{~T}$ model, market segments are represented; they are segmented by census division, residential area type (urban, suburban, or rural), attitude toward novel technology (early, majority, or late adopter), driving pattern (daily distance distribution), and availability of recharging stations at home and at work. Consumer purchase probabilities depend on these consumer attributes; on vehicle attributes such as price, fuel economy, range, and make and model diversity; and on other variables including fuel prices and vehicle purchase incentives. They examined the projected sales of BEVs under various assumptions about battery costs (which were reflected in BEV prices) and the availability of charging at home, work, and public locations.

They projected sales of several thousand BEVs per year by the year 2025; the sales would depend strongly on battery costs and less strongly on the availability of charging stations. Sensitivity to charger availability, particularly chargers at home, was higher when lower battery costs were assumed. The low sales projections would indicate a large barrier to adoption of BEVs. Lin and Greene concluded that at the battery costs used in these model runs ( $\$ 400$ to $\$ 750 / \mathrm{kWh}$ ), vehicle price remained a significant barrier.

Lin and Greene's results indicate that although range limitations can restrict the adoption of range-limited vehicles, future sales of these vehicles depend on the distribution of driving distance requirements as well as vehicle price, the availability of rechargers, and other variables. Lin and Green did not consider the time required for recharging but noted that it might also be a significant factor. 
It is difficult to isolate the effect of a limited vehicle range on the vehicle's adoption rate, however, vehicle range is clearly important to drivers. The value varies widely, depending on the driver's mobility needs and adaptability and on the actual range of the vehicle. The range limitation barrier is most severe for vehicles with a short range, with the implied value of increased range increasing with the reciprocal of range; in other words, an increase of 1 mile is twice as valuable to the owner of a vehicle with a 50-mile range than the owner of one with a 100-mile range, other factors being equal.

An important observation is that the severity of the limited range varies widely between consumers, depending on their driving needs, ability to adapt (availability of another vehicle or other travel modes), and other characteristics. Further work is need to better understand the dependence of the range-limitation barrier on these other factors, so that instead of assigning a single value to the severity, the potential market size can be estimated, and policies can be designed to lower this barrier in places where policies are able to act on the appropriate factors.

While the value of vehicle range varies widely depending strongly on the actual range and on consumer and household characteristics, it appears that there are many consumers who are unwilling to even consider a vehicle with a very limited range. For such consumers, the value of this barrier is comparable to that of the vehicle purchase price, which gives a rough upper bound for the effective cost of this barrier. For other consumers, the barrier is much lower. Much of the variability arises from differences in the driving needs of different households. Rather than estimate a range of effective cost of the range limitation, it may be more useful to estimate the fraction of consumers or households who might consider purchasing a range-limited vehicle.

The distribution of trip distances must be considered when assessing the potential market for rangelimited vehicles, such as BEVs. And because charging times for BEVs are typically hours, the distribution of times when the vehicle can be charged must also be taken into account. Unfortunately, tripby-trip data and data on time spent at locations where vehicles can be charged are limited. A few datasets with such details have been collected and analyzed, as described in the following text. Such data are useful for estimating parameters in vehicle choice models, and they can be used to roughly estimate the size of the potential market for limited range vehicles.

The NHTS and other large, nationwide surveys have been used to draw conclusions relevant to the potential market size for plug-in vehicles [both BEVs and plug-in hybrid electric vehicles (PHEVs)]. The Vyas et al. (2009) report relates that according to the National Housing Survey (USHUD 2006), in 2005, $51.5 \%$ of U.S. residences were single, detached units with a garage or carport, but $92.4 \%$ of single, detached units built during 2000-2005 had a garage or carport.

Use of NHTS data requires assumptions about how often plug-in vehicles are charged, since survey samples were one-day samples. The distance driven between recharging is more relevant than the distance driven daily. Estimating the distance driven between possible charging locations requires trip-by-trip data over many days, including information about the destination of each trip.

Data from instrumented vehicles over multiple days are therefore valuable for quantitatively assessing the potential use of and market for plug-in vehicles, particularly to assess the impact of range limitations of BEVs. Pearre et al. (2011) analyzed data collected from several hundred vehicles in the Atlanta, Georgia, area that were instrumented with data recorders that logged vehicle position, time, and several operating variables. Data were recorded in 1-second intervals when the ignition was on. A total of 363 vehicles were monitored for $75 \%$ or more of the days in one year. Of these vehicles, $9 \%$ were never driven more than 100 miles on any day, and 50\% were driven 313 miles or less on any day. The monitoring results suggest that if a BEV was always charged once a day, a BEV with a 100-mile range could be driven by $9 \%$ of these drivers without foregoing any trips or making other adaptations (such as using an alternate vehicle or travel mode). To satisfy 50\% of these drivers, a vehicle would need a range of 313 miles. They observed that longer trips were much less frequent, and for drivers willing to make adaptations on two days per year, a 10-mile range BEV would meet the needs of $17 \%$ of drivers, and if they were willing to 
adapt on six days per year, a 100 -mile BEV would suffice for $32 \%$ of drivers. While this does not mean that these fractions of drivers would necessarily purchase BEVs, it is a quantitative measure of the size of the potential market for a range-limited vehicle, depending on the ability and willingness of drivers to make adaptations. Pearre et al. (2011) noted that the Atlanta area has the second-largest daily vehiclemiles traveled per capita of the 30 largest urbanized areas in the United States. While these data might not be representative of typical U.S. metropolitan areas, Pearre et al. suggested the analysis provided a conservative estimate of drivers' need for vehicle range.

Tamor and Gearhart (2011) examined another data set from instrumented vehicles: records of 132 vehicles in Minnesota, which included records of trips that occurred over about one year. Tamor and Gearhart estimated the fraction of drivers who could make the recorded trips with BEVs having different ranges. They estimated few (less than 1\%) could make all their trips in a BEV with a range of 100 miles without making adaptations. If drivers were willing to adapt on three days per year, then about $5 \%$ could make the remainder of their trips with a 100 -mile range BEV, and just over $20 \%$ could do that in a 150 mile range BEV. These estimates differ somewhat from those of Pearre et al. (2011), presumably due to differences in the driving patterns of the populations selected and to differences in the methodologies used. Qualitatively, however, similar trends were seen, including sensitivity of the number of days drivers are willing to adapt to the range limitation. Both studies indicate that even if drivers are willing to adapt, the potential market size for range-limited vehicles may be a small fraction of drivers.

Both of these studies show the value of detailed trip-level data over long time periods for assessing range requirements. Larger data sets for more geographical regions, together with demographic and other data characterizing the population, are needed to better quantify the effect of limited range on potential market size.

Tamor and Gearhart (2011) were able to fit daily driving distance distribution with a four-parameter function. They suggested that this empirical function could be used to estimate an individual's driving distance distribution if the four parameters could be defined, but these could be estimated from four pieces of data for that individual and his or her vehicle:

- Miles driven annually

- Days per year the vehicle is used

- Days per week the individual commutes

- Round-trip distance of the commute.

With these data, and some information or assumptions about vehicle characteristics and prices of fuel and electricity, the fuel savings realized by an individual driving a PHEV over a conventional vehicle could be estimated. The number of days that a limited-range vehicle would have insufficient range could also be estimated, but only very roughly, since this estimate would be sensitive to the "tails" of the distribution. The approach, if further validated, could be a valuable tool for informing individuals about potential fuel savings of PHEVs customized to their driving pattern, and it would even allow individuals to assess how sensitive savings might be to changes in their driving. This would directly address the barrier of uncertainty discussed in Section 4.6 for consumers who are considering whether to purchase a PHEV, since they could more accurately estimate the predicted fuel savings on the basis of a record their actual driving.

Data from larger-scale projects, such as the Electric Vehicle (EV) Project funded by the U.S. Department of Energy (DOE) with industry partners that monitors the use of several thousand plug-in vehicles (Chevrolet Volt and Nissan Leaf) and the EV service equipment that is used to charge them, will provide useful data from drivers in several states under a wide range of conditions (EV Project 2012).

These results clearly show that a severely range-limited vehicle faces a large barrier to adoption by a significant fraction of households who are not willing to consider such a vehicle. However, the fact that there are consumers who have purchased such vehicles indicates that the magnitude of the barrier ranges 
from zero to comparable to the vehicle price (i.e., some consumers would not consider purchasing a vehicle with a very limited range). This indicates the diversity of consumer needs and preferences, which depend on circumstances that include the availability of fueling and charging stations or from fueling/charging time. These are discussed in the next section.

\subsection{Value of the Availability of Fueling and Charging Stations}

Clearly, if a vehicle runs on only one fuel, this fuel must be widely available for the vehicle to be adopted. Greene (2001) reviewed work on assessing the value of fuel availability. One measure of availability is the fraction of fuel stations offering the fuel. Surveys of diesel vehicle owners indicate that if the alternative fuel is available at about $10 \%-20 \%$ of the currently existing stations, this barrier is reduced to a minor concern (Sperling and Kitamura 1986; Sperling and Kurani 1987). At lower percentages, the barrier becomes more significant, and it is of very high concern for percentages close to zero. From a review of the surveys, Greene was unable to statistically distinguish between different functional forms for implied value that gave very different values at zero availability; that is, the implied value at low availability is high but very uncertain. However, survey results are consistent with a functional form that decreases rapidly from a large value near zero availability and decreases more slowly with increasing availability to near zero above $20 \%$ availability. For the value of fuel availability, Greene suggested an exponentially decreasing function with a value of $\$ 7,500$ (in 1990 dollars) at zero (no availability), going to $\$ 1,750$ at $5 \%$ availability and $\$ 1,000$ at $10 \%$ availability. In current dollars, the value would be somewhat larger but certainly on the same order of magnitude.

The effect of fuel availability is coupled with vehicle range, since fuel availability is more critical for range-limited vehicles. Moreover, the distribution is important. For example, if the $10 \%-20 \%$ of stations that offer a fuel are located in only a few cities, consumers outside these cities (at least those beyond the vehicle range) are faced with no availability. Effective vehicle range depends on station density, since at low densities, vehicles need to travel more distance while searching for and traveling to stations, reducing the effective range. If fuel stations are likely to offer an alternative fuel only where demand is sufficient, then those stations will probably not be uniformly distributed. This interdependence was examined by Stephan and Sullivan (2004) and Struben (2006), as discussed in Section 4.4.

It is difficult to capture this spatial interdependence in vehicle choice models. However, by modeling only a specific spatial area or by explicitly modeling market segments or regions, each with its own measure of fuel availability, vehicle choice models can be used (Lin and Greene 2011). Further research is needed to understand this barrier.

\subsection{Value of Refueling Time}

The cost of refueling time can be estimated based on assumptions about the value of travel time. The value of time to drivers on trips varies widely depending on the circumstances of the driver and the purpose of the trip. A large number of studies have made estimates of travel time. Small and Verhoef (2007, pp. 52-54) reviewed many such studies and found that estimates of the value of time for personal trips varied widely by circumstance, with most estimates being between $20 \%$ and $90 \%$ of the travelers' gross wage rate, and an average value being $50 \%$ of the wage rate. Small and Verhoef also reviewed utility theory arguments that imply that if people tend to trade off time spent in various activities including work, a significant portion of the value of travel time should be proportional to the wage rate, even time spent in nonwork travel.

A value of $50 \%$ of the salary implies that for fueling times on the order of several minutes, the cost barrier due to fueling time is negligible. This seems reasonable, since a negligible barrier is expected for vehicles with fueling times that are comparable to conventional vehicle fueling times.

For BEVs, recharging can take hours, but the use of a time value of $50 \%$ of salary is unrealistic, since recharging can usually be done when the vehicle is not in use (e.g., overnight). However, time spent 
recharging that detracts from time spent in other activities that have value to the driver would be presumably valued accordingly. On the basis of the review by Small and Verhoef (2007), it appears that some fraction of salary would be reasonable to use. However, the value of time spent recharging that actually detracts from other activities is difficult to estimate. It would likely be a small fraction of total recharging time. The future development of very-high-rate chargers that would greatly reduce recharging time would render the case more similar to that of fuel cell vehicles (FCVs), but the future availability of such chargers is difficult to estimate.

Hidrue et al. (2010), in the survey discussed in Section 4.1, asked participants about their preferences for BEV attributes in comparison with the attributes of gasoline vehicles. They found that respondents were willing to pay $\$ 425$ to $\$ 3,250$ per hour of reduction in charging time for a 50-mile charge. As noted above, the willingness to pay for an increase in a range of 1 mile was $\$ 35$ to $\$ 75$, depending on the range of the vehicle considered. Hidrue et al. asked respondents to consider BEVs with driving ranges of 75300 miles. Hidrue et al. analyzed information from respondents to determine whether certain characteristics of household or vehicle purchasers are correlated with preferences for or against new vehicle technologies. They found willingness to consider a BEV for the next car purchased was positively correlated with the following characteristics of the respondents:

- Being younger

- Expecting higher gas prices in the next 5 years

- Having made a shopping or life style change to help the environment in the last 5 years

- Likely to buy a hybrid gasoline vehicle on their next purchase

- Having a place to install a BEV outlet at home

- Likely to buy a small or medium-sized passenger car at next purchase

- Having a tendency to buy new products that come into the market

- Having to make at least one drive per month that is longer than 100 miles.

The last finding is counterintuitive, but Hidrue et al. noted that drivers who drive longer distances pay more for fuel and stand to save more from BEVs. They also found no significant correlation with being a multicar household.

Presumably PHEV purchasers would want to keep the vehicle batteries charged when possible to realize the benefits of electric operation, so faster charging would have value, but recharging times for PHEVs are shorter than those for BEVs, and drivers have the option to use fuel, so the value of recharging time to PHEV owners may be less than that for BEV owners. No studies comparing the value of charging time for PHEV owners and BEV owners were found.

The results just discussed suggest that rather than attempting to estimate the effective cost barrier from refueling/recharging time, it is probably more useful to examine what fraction of vehicle purchasers would consider BEVs, assuming that this would depend on the availability of chargers that could be used during times that would not interfere with other activities. The range of the vehicle must be considered at the same time, taking into account the drivers' patterns of vehicle use and the distributions of trip distances, as described previously. For BEVs, it isn't useful to consider the value of recharging time in isolation. While a number of models include variables for vehicle range, availability of alternative fuel, and refueling time in a utility function, a more integrated approach is possible. This is an area of ongoing research. One study considering refueling time, vehicle range, and availability of fueling/charging stations in combination is discussed in Section 4.4.

\subsection{Combined Valuation of Vehicle Range, Fuel Availability, and Refueling Time}

Some studies estimate the effects of limited vehicle range in combination with fuel availability and fueling time. In one such study, Lin and Greene (2010b) compared the consumer valuation of vehicle 
range for BEVs and FCVs. They reviewed some previous estimates of values of consumer costs or disutilities of limited refueling/recharging availability for FCVs, which ranged widely, from a few hundred to a few thousand dollars, depending on the fraction of fueling stations offering hydrogen. They suggested that the disutility of limited vehicle range should be evaluated for vehicles, with a range being chosen to minimize the net cost to the consumer, recognizing that range is traded with other vehicle attributes. If range is arbitrarily chosen, the effective disutility in terms of lost value from other attributes may make the vehicle appear more costly (i.e., less desirable to consumers), which would inflate the barrier to adoption above that for a vehicle with an optimal range. To determine the optimal range for FCVs, Lin and Greene proposed a disutility function consisting of five terms, including costs of (or loss in utility from) (1) on-board hydrogen storage, (2) loss of interior space, (3) travel time and hassle of refueling, (4) fuel wasted while searching and traveling to stations, and (5) time spent pumping fuel. The optimum range was selected to be the one that minimized this disutility function. Lin and Greene estimated travel time and hassle disutility by calibrating to data on 5,830 gasoline and diesel vehicles. Other terms were estimated from assumed values of FCV fuel economy, on-board hydrogen storage cost, and vehicle lifetime. The present value of the disutility of limited range/refueling availability was estimated for the optimum value of the range. The estimated costs depended on the fraction of fueling stations that offered hydrogen. Estimates were significantly lower than the estimates they reviewed that were based on surveys.

Lin and Greene (2010b) suggested a slightly different disutility function for BEVs. They noted that it is more likely that BEV owners than FCV owners will be able to recharge their vehicles at home but that the limited range will impose a cost of disutility. The disutility function for BEVs includes the cost of the battery, the disutility of lost interior space, and the disutility of "range anxiety." The range limitation (range anxiety) disutility was estimated to be $\$ 50$ for each day per year that a driver's travel exceeded the range of the BEV. Similar to Lin and Greene (2011), Lin and Greene (2010b) generated daily driving distributions for modest, average, and frequent drivers that represented quantiles of driving distance distributions of drivers in the 2001 NHTS (FHWA 2005). Modest, average, and frequent drivers drove averages of 40,70, and 124 kilometers $(\mathrm{km})$ per day $(24.8,43.5$, and $77.1 \mathrm{mi}$ per day), respectively. Battery costs were estimated based on $\$ 500$ per kilowatt-hour. Lin and Greene $(2010 \mathrm{~b})$ estimated the optimal ranges of BEVs for modest, average, and frequent drivers, which ranged from slightly over 100 $\mathrm{km}$ for the modest driver to $300 \mathrm{~km}$ for frequent drivers. The disutility function ranged from approximately $\$ 12,000$ for the modest driver to $\$ 30,000$ for the frequent driver, due mostly to the battery cost. The range anxiety term was slightly over $\$ 1,000$ for modest drivers and $\$ 6,000$ for frequent drivers.

Stephan and Sullivan (2004) used an agent-based model, with agents representing drivers and fuel station operators, to model the transition to a hydrogen-based transportation system. The utility function they used for driver agents deciding whether to buy a hydrogen-powered vehicle included vehicle price, operating costs, an "inconvenience" factor and a "worry" factor. The inconvenience factor represented the disutility of searching for hydrogen fueling stations and depended on the number of stations offering hydrogen located near the agent's workplace or home. The worry factor represented the driver's range anxiety and depended on the distance between successive hydrogen stations that the driver passed on all previous trips. They were able to model the interaction between drivers of hydrogen-powered vehicles and fuel suppliers. Driver agents would choose between a conventional or hydrogen-powered vehicle. Drivers would travel on a 100-by-100 cell grid that was set up with routes and destinations. Drivers of hydrogen-powered vehicles would plan routes based in part on the location of fueling stations that provided hydrogen, and fuel supplier agents would establish fueling stations at locations in the grid and would decide whether to offer hydrogen (with a significant investment in equipment), depending on the local traffic. Stephan and Sullivan simulated the co-evolution of the hydrogen vehicle and hydrogen retail markets. Depending on initial conditions, including the initial density and distribution of fueling stations, some simulations showed a successful adoption of hydrogen-powered vehicles (sales monotonically increasing to a plateau), while some showed transition failure (sales of hydrogen-powered vehicles eventually decreasing to near zero). They found that the relative cost of hydrogen-powered vehicles 
versus conventional vehicles and the density of hydrogen fueling stations were important in determining fleet penetration and in determining whether the numbers of hydrogen-powered vehicles and fueling stations were stable or decayed to zero. Results were also sensitive to the initial placement of hydrogen fueling stations. If locations were chosen to minimize driver agents' worry and inconvenience factors, it was more likely that hydrogen vehicles would penetrate the market. The relative weights of the inconvenience and worry factors were also important, indicating that the relative importance to consumers of refueling near work or home versus the availability of fuel on longer trips influenced the outcome.

The density and distribution of hydrogen stations are critical to successful adoption of hydrogen-powered vehicles. Although it is difficult to derive a value for fuel availability from this study, that value is clearly a very important factor. The magnitude of several thousand dollars that was suggested is consistent with this observation.

Struben and Sterman (2007) (also see Struben [2006]) developed a suite of systems dynamics models to examine the dynamics associated with adopting new alternative fuel vehicles and to study their dependence on various factors, one of which was a spatially explicit model of alternative fuel adoption coupled with development of the fuel supply infrastructure. In this model, fuel suppliers endogenously decided where to locate alternative fueling stations based on their perceived profitability, which depended on fuel demand at that location and the density of competing stations nearby. The drivers' perception of the utility of alternative fuel vehicles depended on the risk of running out of fuel and the expected refueling time. The adoption rate of vehicles depended on the consumers' perceived utility of vehicles and familiarity with them, which depended on social interactions and marketing. Drivers decided whether to travel to a location based on their expectation of travel time, the risk of running out of fuel, and the likely time and effort required to find fuel. A log-normal distribution of trip distance was assumed. Drivers of alternative fuel vehicles were assumed to fuel up more frequently if they lived in an area with a low density of fueling stations that offered the fuel they needed.

The spatially explicit model was calibrated to California, with the population being spatially distributed according to 2003 statistics and with 17.1 million vehicles being spatially distributed the same way as the population density. Trip decision parameters were set to give an average of 12,000 miles per vehicle per year. As a test, simulations were run with only conventional vehicles, starting with gasoline stations being uniformly distributed, but with only $10 \%$ of the current number of stations and no alternate fuel stations. The model was allowed to equilibrate (stations opened or closed endogenously), and the resulting distribution of stations agreed fairly well with the actual distribution of gas stations.

Struben and Sterman (2007) then used the model to project the locations and densities of alternative fuel stations and the market penetration of alternative fuel vehicles in the state of California, assuming that alternative fuel stations were heavily subsidized for the first 10 years. The penetration of alternative fuel vehicles was predicted to be slow, and the number of alternative fuel vehicles and density of alternative fuel stations remained low except in the densely populated areas around Los Angeles, San Diego, and San Francisco. The number of alternative fuel vehicles and stations did not approach the steady-state value until after 25 years. Struben and Sterman (2007) tried to explicitly capture the interdependencies of range anxiety, social interactions, vehicle use decisions, and driving patterns and to include the spatial effects of route networks and population density distributions. The value of their model is not in its ability to predict outcomes for alternative vehicle adoption but in its ability to show the complexity of the interdependency of these factors. An important conclusion is that alternative fuels (e.g., hydrogen) that have little or no existing distribution and sales infrastructure may develop around population centers first and then develop further only under very favorable conditions. It is difficult to estimate the adoption of alternative fuel vehicles without basing them on assumptions about these conditions, which will probably differ from location to location. It is not possible or even meaningful to isolate the effect of vehicle range, fuel availability, or consumer familiarity from the many factors and conditions with which they interact. Simulations can help greatly in examining sensitivities and exploring spatial distributions of adoption patterns, but simple estimates using "average" conditions are most likely wrong and probably misleading. 
Although specific values for the magnitude of the barriers due to limited vehicle range, fuel availability, or refueling time cannot be derived, Struben's results indicate that these barriers can significantly influence the adoption of alternative fuel vehicles. When the range and fuel availability of these vehicles are not sufficient, the successful introduction of these vehicles is very unlikely. These factors can represent a very large barrier, consistent with estimates discussed previously.

Considering these results, the value for the barrier represented by a combination of limited vehicle range, limited fuel availability, and long refueling time is on the order of $\$ 1,000$ to $\$ 10,000$. This range must be considered only a rough order of magnitude, given the wide diversity of driving needs, local availability of charging/fueling stations, and adaptability of different drivers. Clearly there is a significant segment of consumers who will not consider a range-limited vehicle that is not convenient to charge or fuel, so for these consumers, the barriers is comparable to the vehicle price. However, there are some consumers who have purchased such vehicles, indicating at times, there is little or no barrier. Research is now being done on how to estimate the size of the potential market for these vehicles, but estimates are highly uncertain even for the near term (next few years).

\subsection{Value of Diversity of Vehicle Makes and Models}

Consumers shopping for a new vehicle want bundles of features. If technologies that increase fuel economy are not offered in a desired package, consumers may forgo the technology. Some consumers are loyal to their favorite brands and tend not to buy a new-technology vehicle if it is not offered by their preferred brand. The wider the range of makes and models in which a technology is available, the more likely it is that consumers who desire the technology will find it available with other features they also want.

For a given technology, this barrier can be quantified in terms of the fraction of models that are available with the technology,

$$
\frac{n_{i}}{N}
$$

where

$$
\begin{array}{ll}
n_{i} & \text { is the number of models with technology } i \\
N & \text { is the total number of vehicles on the market }
\end{array}
$$

Greene (2001) explains how this ratio can be related to utility and sales share in a multinomial logit discrete choice model. In this case, if the utility of vehicles is equal (to isolate the effect of make and model availability), the probability of purchasing a vehicle with a technology is proportional to the fraction of models with technology $i$, and the utility of the availability of the technology in $n_{i}$ out of $N$ total vehicle choices is equal to the natural logarithm of this fraction

$$
\ln \left(\frac{n_{i}}{N}\right)
$$

The implied value is then the utility, as given by Equation 10 divided by the coefficient of vehicle price. Greene (2001) explains that while this is the implied value, if all makes and models have the same expected utility and if consumers prefer certain makes or models, then the implied value is slightly less than this value. Such consumer preferences can be described by using a nested, multinomial logit model, as discussed in the appendix. Greene used a price coefficient for alternative fuel vehicles in his nested, multinomial logit model to estimate implied values of diversity of several hundred dollars for $\operatorname{ratios} n_{i} / N$ close to 0.5 to several thousand dollars for ratios close to 0.01 (typical of a new technology). These 
approximate values indicate that this barrier is very significant (roughly $\$ 100$ to $\$ 1,000$ in magnitude) for new technologies that are offered in only a few percent of models.

\subsection{Value of Uncertainty and Unfamiliarity}

If a consumer who is considering purchasing an advanced technology vehicle is uncertain about its benefits, then this uncertainty may be a barrier. Although it is related to costs, uncertainty is included in non-cost barriers discussed here because the uncertainty itself, apart from any difference in cost, can be a barrier to vehicle purchase. Greene (2011) examined the effects of uncertainty of the value of fuel economy on vehicle purchase by using a model that incorporates a risk-averse utility function in a Monte Carlo simulation. Greene showed that when the future savings that a consumer could realize from investing in a more fuel efficient vehicle are uncertain, risk averse behavior results in a bias against making such an investment. This is not simply because future savings may be less than the incremental cost of the more efficient vehicle, but because the value of future savings as perceived by a risk-averse consumer depends on the uncertainty of the savings. People tend to assign uncertain future losses a disproportionally large disutility; that is, future losses are weighed more than future gains, if losses or gains are uncertain. This can be represented by a nonlinear utility function that weights losses more heavily than gains, depending on the uncertainty. Greene estimated the utility of purchasing a vehicle with an average fuel economy of $28 \mathrm{mpg}$ instead of a similar but less expensive vehicle with an average fuel economy of $21 \mathrm{mpg}$. To examine the effect of uncertainty in the fuel savings from such a vehicle over its lifetime, he estimated the savings by using random values for actual fuel economy, vehicle lifetime, price of fuel, vehicle-miles driven per year, and the incremental cost of increased fuel economy (the difference in price between the two vehicles). Greene assumed that actual fuel economy, vehiclemiles per year, and incremental price were random, with triangular distributions. The width of each of these distributions was set to match available data.

Specifically, Green assumed that the two-standard-deviation confidence interval of the fuel economy distribution was $\pm 7 \mathrm{mpg}$, to match the spread of fuel economy values reported in the fueleconomy.gov "Your MPG" database. He assumed that the vehicle price difference ranged from $\$ 655$ to $\$ 1,345$, with a mean of $\$ 655$, and that vehicle-miles driven decreased $4.5 \%$ per year, starting from an average of 15,000 miles and a $95 \%$ confidence interval of 14,000 to 17,000 miles in the first year. Fuel prices were assumed to be log-normally distributed, with a mean of $\$ 2.05$ per gallon, a $5 \%$ probability of prices exceeding $\$ 2.63$ per gallon, a $95 \%$ probability that prices would exceed $\$ 1.78$ per gallon, and a shift parameter of $\$ 1.72$ per gallon (zero probability that prices will average below $\$ 1.72$ per gallon). These parameters were chosen to match fuel prices in the DOE Energy Information Administration's 2007 reference, high oil price, and low oil price cases over 2010-2023. Fuel savings were discounted by $16.5 \%$ per year. Vehicle lifetimes were assumed to be distributed according to an empirical distribution published as Table 3.8 in Davis and Diegel (2007).

Greene found that savings were broadly distributed around a mean of $\$ 405$, with a significant fraction of the distribution being less than zero. In other words, for many cases, net savings were negative (which might easily be the case for a car that was not driven many miles per year and had a short life). By using the nonlinear utility function to represent uncertainty loss aversion bias, the same simulations were run. These resulted in a distribution that was skewed to negative values by the utility function. The average perceived value of the fuel savings (net the purchase price) had a mean of $-\$ 32$. This indicates that uncertainty loss aversion bias can make a good investment appear undesirable, and the magnitude can be significant - enough to outweigh the average benefit.

Uncertainty in returns on an investment can make the investment less desirable, even if the expected net present value is positive, if other options are available to the investor (including the option to forego the investment or delay or modify the terms of the investment) and if the uncertainty decreases with time or with additional information. Investment strategies under uncertainty have been developed based on real option valuation theory (Dixit and Pindyck 1994), but while this theory may show why apparently 
attractive investments in more efficient or economical goods might not be optimal, it is not intended to represent actual mass consumer decision-making. It is intuitive, however, that consumers, when faced with an uncertain "bet" (i.e., a decision whether to spend more money on a more fuel-efficient vehicle in order to save money on fuel in the future), may not make the bet, even if it appears to be a good one on average. Greene concluded that uncertainty can represent a significant barrier and showed that under not very restrictive assumptions, uncertainty loss aversion bias can cause consumers to value future fuel savings less than an equivalent change in vehicle price. Green concluded that fuel economy would be more attractive to consumers if the uncertainty in the actual fuel economy that they would realize in the future could be decreased.

How fuel economy is reported can contribute to the confusion and uncertainty of consumers. Greene et al. (2009) discusses the implications of research by Larrick and Soll (2008) that indicates that consumers are confused about the relationship between fuel economy (measured in mpg) and fuel consumption (gallons per mile), and that this contributes to inaccurate assessments of the value of fuel economy. Many consumers perceive an increase in $10 \mathrm{mpg}$ from 40 to $50 \mathrm{mpg}$ to be equal to a $10-\mathrm{mpg}$ increase from 20 to $30 \mathrm{mpg}$. In fact, the increase from 40 to $50 \mathrm{mpg}$ reduces fuel consumption by 0.50 gallon per 100 miles, while an increase from 20 to $30 \mathrm{mpg}$ reduces fuel consumption by 1.67 gallons per 100 miles. For a car driven 10,000 miles and a fuel price of $\$ 3.50$, the fuel savings is $\$ 175$ in the first case (40 to $50 \mathrm{mpg}$ ) and $\$ 583$ in the second case (20 to $30 \mathrm{mpg}$ ). It has been recommended that fuel consumption per mile be reported rather than fuel economy in mpg, or that, at the least, estimated fuel savings in dollars per year be indicated (both of these are displayed on the current Monroney label or "window sticker" on new cars, along with fuel economy in mpg). Labels and other measures to better inform consumers are discussed in Section 5.1.

Apart from uncertainty in fuel savings, uncertainty in the cost for maintenance and parts and in the vehicle's resale value can be a barrier to adopting new technologies. Although these uncertainties have not received as much attention as uncertainties in fuel economy, some consumers (those considering a plug-in vehicle, for example) are probably concerned about battery life, replacement cost, and the warranty on the battery. These concerns may not be a significant barrier for many consumers unless many early adopters experience failures or problems. However, as noted above, to consumers who consider potential future losses, these may be weighted more heavily than potential future savings if there is significant uncertainty.

In addition to uncertainty about specific benefits that are offered by advanced technology vehicles, an unfamiliarity with or a lack of awareness about new types of vehicles may keep some consumers from considering purchasing such vehicles. How an awareness of new types of vehicles spreads within a population of consumers, and how this awareness might influence a consumer's adoption of these vehicles, was studied by Struben and Sterman (2007), as mentioned in Section 4.4. They used their systems dynamics model to examine the role of awareness and consumer interactions on the adoption of alternative fuel vehicles. In one of their models, coupled differential equations described:

- Vehicle stock by vehicle type, each with attributes (performance, cost, range, etc.)

- Vehicle sales by type, dependent on consumer choice

- Consumer choice, dependent on consumers' familiarity with vehicle types and willingness to consider each type

- Consumers' familiarity with new alternative fuel vehicles, dependent on social interactions with other consumers familiar with these vehicles and on the number of such vehicles on the road

- Consumers' willingness to consider an alternative fuel vehicle, dependent on attributes and on "complementary assets" consisting of service, parts, maintenance, and fuel distribution infrastructure. 
With regard to the last bullet, willingness to consider an alternative fuel vehicle depended on exposure through advertising, the fraction of vehicles on the road that were alternative fuel vehicles, and word of mouth or other interactions with drivers. If exposure to alternative fuel vehicles was infrequent, then willingness to consider the vehicles was assumed to decay. The functional form used for willingness to consider contained parameters describing the influence of marketing, interactions between consumers (drivers), and the rate of decay of willingness to consider in the absence of marketing or interactions.

Struben and Sterman (2007) found that the market share of the alternative fuel vehicle grew initially under favorable conditions (presence of a marketing campaign and sufficiently strong interactions), but the market share would decay if these conditions were not maintained for a sufficient time. Both an effective marketing campaign and exposure through social interactions were necessary for the market share to increase to a self-sustaining level. Due to the long lifetime of vehicles (assumed to be 12 years), the marketing campaign would have to be in place for 20 years for a successful transition to alternative fuel vehicles to occur (attainment of self-sustaining market share). By varying parameters in simulations, they determined that successful transitions were favored by:

- Higher effectiveness of social interactions

- Higher marketing effectiveness

- Better performance of the alternative fuel vehicle than the competing vehicle

- Shorter average vehicle life

- Higher growth rate of the total fleet.

The dependence on these factors was nonlinear, and there was a decreasing response to increases in many of these parameters much beyond the minimum value that enabled a successful transition.

Although Struben and Sterman chose parameter values for the model on the basis of available consumer data, they did not calibrate the model to actual vehicle sales data. However, their results indicate that positive social interactions and marketing are important - even essential - to achieving successful market penetration. In their model, consumer awareness of advanced technology vehicles developed as a function of the effectiveness of marketing, social interactions, and the fraction of such vehicles in the on-road stock. Consumer awareness depended strongly on marketing when the fraction of vehicles was low, and since this fraction grew slowly due to the slow turnover of the fleet, a long-term marketing campaign was necessary until the advanced vehicle stock increased enough to raise consumer awareness. For new advanced technology vehicles, unfamiliarity is a high barrier and one that can take years to overcome.

Although the value of uncertainty and lack of awareness depends on the level of uncertainty, the degree of consumers' risk aversion, their level of awareness, and many poorly understood factors, the results just reviewed indicate that this value is on the order of several hundred dollars, possibly ranging from $\$ 100$ to $\$ 1,000$.

\subsection{Consumer Predispositions and Perceived Differences between Vehicles}

Many factors other than those considered previously (including some that are less tangible than vehicle attributes) can influence consumer choices. These include a consumer's preference for (or dislike of) certain vehicle types that is a result of real differences in vehicle functionality (e.g., cargo capacity or towing capability of pickups), or of real or perceived differences in safety, or subjective reasons (e.g., a preference for hybrids since they are "green"). Note that in the case of consumer preferences or predispositions for certain types of vehicles, the "effective cost" may be negative; that is, consumers may be willing to pay more for a vehicle that they have a preference for, even for nonmonetary reasons. These can be included in utility and discrete choice models as additional factors or dummy variables. It is impossible to capture all such factors in vehicle choice models, but two examples are discussed here: 
- One examining a consumer preference for light trucks because of their increased safety in multiple vehicle crashes

- One examining influences of lifestyle, personality, and attitude on vehicle preferences.

Following these two examples, two studies based on in-depth interviews of recent purchasers of hybrid electric vehicles (HEVs) or PHEVs are briefly discussed.

Li (2010) developed a vehicle choice model to evaluate a consumer preference for light trucks over passenger cars because of the trucks' crash safety. Li examined data on serious accidents involving cars and light trucks and concluded that in multiple vehicle crashes, light trucks (including sport utility vehicles, pickup trucks, and passenger vans) offer better protection for occupants than do cars, but occupants in light trucks are less safe in single-vehicle crashes. He also found that light trucks pose greater risks to occupants of other vehicles in multiple-vehicle crashes than do cars. It was found that overall, light trucks are safer than cars for vehicle occupants, and the safety advantage of light trucks increases as more of them are in service. Li defined a statistic - equivalent fatalities - that combined rates of fatalities and serious injuries from motor vehicle crashes. An equivalent fatality was taken to be a fatality or 20 incapacitating injuries. The factor of 20 was based on a National Safety Council estimate of the average comprehensive cost per death, which was about 20 times of that per incapacitating injury. Li estimated these for passenger cars and for light trucks from National Highway Traffic Safety Administration crash statistics by using the following relationship:

$$
\begin{aligned}
& E F_{c}=\left(D_{c c} S_{c}+D_{c t} S_{t}\right) P_{c}^{M V}+D_{c} P_{c}^{S V} \\
& E F_{t}=\left(D_{t c} S_{c}+D_{t t} S_{t}\right) P_{t}^{M V}+D_{t} P_{t}^{S V}
\end{aligned}
$$

where

$E F_{c}$ is the number of equivalent fatalities per occupant of a car per year

$E F_{t}$ is the number of equivalent fatalities per occupant of a light truck per year

$D_{j k} \quad$ is the probability of an occupant in a vehicle of type $j$ suffering an equivalent fatality when colliding with a vehicle of type $k$

$S_{c} \quad$ is the share of cars of all vehicles on the road

$S_{t} \quad$ is the share of light trucks of all vehicles on the road

$P_{j}^{M V}$ is the probability of being in a multiple-vehicle crash for vehicle type $j$

$P_{j}^{S V}$ is the probability of being in a single-vehicle crash in vehicle type $j$

Li estimated that $E F_{c}$ was $1.309 \times 10^{-4}$ per car per year and $E F_{t}$ was $1.172 \times 10^{-4}$ per light truck per year, indicating the difference in safety of occupants of light trucks over those of cars was $1.37 \times 10^{-5}$, with a standard error of $4.2 \times 10^{-6}$.

In order to investigate whether traffic safety concerns show up in vehicle choice, Li estimated parameters for a vehicle choice model that included consumers' utility for equivalent fatalities. He found that consumers show a preference for light trucks for their safety advantage over cars and estimated that about $12 \%$ of new light trucks sold in 2006 in the United States could be attributed to this preference. From this model, he estimated consumers' willingness to pay for the increase in safety of a light truck over a car. The mean willingness to pay was $\$ 1,945$, with an interquartile range of $\$ 719$ to $\$ 2,608$, with higherincome households willing to pay more. 
This model was a random coefficient model and contained parameters for attributes other than equivalent fatalities. The other attributes included gasoline price, fuel cost in dollars per 100 miles, and probabilities of single- and multiple-vehicle crashes. Li used sales, vehicle crash, and demographic data from 20 metropolitan statistical areas. The estimated willingness to pay for the increase in safety of a light truck over a car does not represent the price premium that a light truck could be expected to command over a car, but it is a measure of consumer preference for light trucks over cars on the basis of their increased safety for occupants, when other variables are controlled for. In this study, consumers' predisposition against certain vehicle types for safety reasons was quantified and estimated to be large.

Choo and Mokhtarian (2004) examined the influence of attitude and lifestyle variables on the type of vehicle that people in the San Francisco Bay area chose for the one used most often. In a survey of area residents, they collected data from 1,904 respondents on vehicle characteristics, demographic variables, and drivers' personality traits and attitudes about travel. Responses to questions about attitudes were reduced to four personality types: adventure seeker, organizer, loner, and calm personality. Responses to attitude questions were reduced to variables indicating whether they disliked travel, were pro-environment, found commuting beneficial, valued travel freedom, found travel stressful, or were prohigh-density living. Responses to lifestyle questions were reduced to four lifestyle types: status seeker, workaholic, family/community-oriented, or frustrated.

By fitting a vehicle choice model, Choo and Mokhtarian quantified correlations between personality, attitude, lifestyle, and demographic variables of drivers and vehicle choice and found a number of significant correlations. For example, they found that drivers who have a stronger dislike for travel are more likely to drive luxury cars and that drivers who are pro-high-density living tend to drive smaller cars (small, compact, and mid-sized) or expensive cars (luxury cars and sport utility vehicles), with the stronger correlation being between pro-high-density living and expensive cars.

They found that although including the personality, lifestyle, and attitude variables increased the explanatory power of the model (the variation in vehicle choice that was correlated with the independent variables), it did so only slightly. With the additional variables, $17.7 \%$ of the information in the data was explained by the independent variables, which is comparable with some other vehicle choice models that Choo and Mokhtarian cited. They noted some limitations in their approach, such as not including details of vehicle characteristics that were readily available (e.g., price, capacity, or horsepower). It is possible that the influence ascribed to attitude and lifestyle variables is partially due to effects of those excluded variables. Also, the model did not segment consumers or nest vehicle choices, which may mean that some vehicle choice probabilities were not properly modeled. Consumers' attitudes, personalities, and lifestyles certainly affect their vehicle choices and travel behavior, but it is difficult to quantify these factors or their influence on these behaviors.

Although Choo and Mokhtarian did not study correlations between attitudes, lifestyle, and the rates of adoption of advanced vehicle technology, consumer attitudes and lifestyles do significantly affect vehicle choice, and can limit adoption rates of certain vehicle types by some consumer segments. This is clearly related to the barrier created by a lack of diversity of makes and models discussed above. But consumer attitudes and preferences appear to influence their opinions and choices of advanced powertrain vehicles, e.g., HEVs or PHEVs vs. conventional vehicles. Attitudes about and perceived differences between advanced technology vehicles and conventional vehicles can influence consumer choices, but perceptions about differences have not been incorporated into the utility functions of most of the vehicle choice models reviewed in this study. Consumer perceptions and feelings about certain types of vehicles and vehicle technologies have been studied on the basis of interviews. Interviews, especially when conducted with recent purchasers of advanced technology vehicles, can reveal much richer information to enable a deeper understanding of how perceptions, feelings, and values influence vehicle purchases.

Consumer preferences are shaped by many factors, most of which are difficult to quantify. The question of why some people prefer vehicles with particular attributes is very complicated. For some car owners, 
their vehicle serves as a symbol that reflects their self-image and communicates something about their values to others. Heffner et al. (2007) interviewed several HEV owners about their motivation to purchase an HEV. The people interviewed had wide-ranging opinions about the implications of HEV ownership. HEV ownership meant not just saving money on fuel or reducing emissions but also "made a statement." Heffner et al. concluded that motivations of early HEV adopters are complex and varied and difficult to reduce to a simple formula. Symbolism is clearly important (if advertising for passenger vehicles is any indication), and policies to promote advanced technology vehicles must consider the possible implications of such symbolism.

Kurani et al. (2010) conducted detailed interviews and made field observations of early PHEV users participating in the PHEV Demonstration and Consumer Education, Outreach, and Market Research Program of the California Air Resources Board. Conducting in-depth interviews and allowing drivers to tell their story allowed drivers' motivations to be better understood. Some, but not all, drivers changed their driving as they used the PHEVs. Some drivers felt good about saving gasoline or helping with the environment, and some wondered about how much money they were saving. Charging behavior was influenced by the drivers' assumptions about the PHEV function; some likened PHEV charging to cell phone charging. For example, one driver would charge only when the battery was low, as she did with her cell phone, not realizing that she could drive more miles electrically with a more fully charged battery. Some drivers were hesitant to charge their vehicle outside their homes if they did not know what was considered proper social etiquette for using public chargers, and some had safety concerns. Some drivers found the in-vehicle display confusing and did not correctly interpret the battery charge indicator.

Kurani et al. (2010) also examined the role of social interactions of a subset of the PHEV drivers in the study. Drivers identified people in their social network who were "very close" and "somewhat close" to the household and then recruited some of these people to participate in the study. Drivers recorded episodes in which they discussed PHEVs, electric drive, or vehicle purchases in general over a multiweek period with the people participating in their network. Both drivers and network participants were interviewed to collect information on their interactions. Kurani et al. found that information about PHEVs flowed both ways, from drivers to others in their network and vice versa; drivers learned about PHEVs from others. Popular models of technology diffusion that assume information about new technologies is transmitted from early adopters to others appear to oversimplify how information about and understanding of new technologies are transmitted within social networks. Preliminary results indicated that social interactions were important. Drivers identified which of the recorded episodes they considered to be the most significant. Kurani et al. found that the reported significance of interactions correlated with the closeness of the person with whom the driver was interacting, the nature of the PHEV benefits discussed (societal or functional), and whether the person with whom the driver was interacting owned an $\mathrm{HEV}$ or had experience with an alternative fuel vehicle.

The above discussion indicates that surveys and interviews are valuable in understanding the motivations for adopting advanced technology vehicles and how the use of vehicles can change in the context of the consumer. As vehicle technologies evolve, a much better understanding is needed of public perception of new vehicle technologies and the future functionalities of vehicles to anticipate the market penetration of these vehicles. New vehicles may be used in different ways, especially if they have capabilities not offered in current vehicles. This understanding will come only as vehicle technology improves and markets for new vehicles develop together.

It is difficult to foresee future vehicle purchasing behavior, travel behavior, vehicle ownership patterns, and attitudes toward vehicle use. Any of these may be quite different in the future. Surveys will no doubt continue to be important sources of information to those interested in vehicle technologies. In the discussions of quantitative estimates of barrier severity or effective cost in earlier sections, it is noted that the estimates range widely, since preferences, circumstances, travel patterns, and other important factors vary widely among consumers. Surveys and interviews are important not only for revealing these consumer-specific factors and for estimating barrier severity, but also for helping researchers understand 
what policy interventions might be useful for addressing barriers and tailoring policies and programs to specific consumer groups. It is difficult to generalize results from local or regional surveys or from surveys of particular segments of consumers, and it is simplistic to try to arrive at a single value for the effective cost of a barrier to an "average consumer." Surveys and interviews can provide essential information for understanding the factors from which barriers arise and how these factors are distributed in consumer populations.

From the results reviewed here, preferences for or dislikes of certain types of vehicles appear to be significant for at least a few consumers, some who have a strong predisposition for some types of vehicles and some who are unwilling to consider some types of vehicle. The range is wide, since predispositions, perceptions, and opinions can vary widely and often depend on feelings and associations related to intangible factors difficult to quantify. For some consumers, strong feelings or preferences about certain types of vehicles may preclude consideration of certain vehicles, in which case, the barrier is comparable to the vehicle purchase price. For others, the preference for certain vehicle types may be large, which would indicate a negative "barrier" or tendency to purchase a certain type of vehicle, even if it cost more than a comparable conventional vehicle (maybe as much as $\$ 1,000$ or more). In cases where an advanced technology is offered only in certain vehicle types, the barrier created is closely related to lack of diversity of makes and models, but it appears that some consumers are predisposed for or against vehicles with certain technologies, e.g., hybrid or plug-in vehicles. While it is very difficult to quantify these preferences, effective costs from $-\$ 1,000$ to $\$ 10,000$ seem consistent with the studies reviewed above, with negative values representing a preference for advanced technology vehicles.

\subsection{Value of Standardization and Regulations}

The effects of standards and regulations that make new technologies easier or safer to use or even transparent to the user are difficult to quantify, and these have not been explicitly taken into account in any vehicle choice models or consumer utility models that the author has found. Such standards and regulations are important, and a lack of adequate standards and regulations can be a significant barrier. A rough magnitude is estimated based on general considerations in Section 5.1.4.

\subsection{Observations on Methods for Quantifying Non-Cost Barriers}

Utility functions, such as those used in multinomial logit models, allow for the estimation of an implied value for vehicle attributes and factors, including range, convenience of refueling, and the variety of models in which a new attribute is offered. Agent-based models provide a different approach to quantifying factors (e.g., range anxiety) and can be used to examine effects of heterogeneity in the population of consumers, interactions between drivers and members of their social networks, and the evolution of vehicle use patterns.

Models provide a means for representing some barriers and parameterizing them; however, an accurate quantification of the severity of barriers is difficult to achieve due to the sensitivity of implied values to the uncertainty in model parameters, to the model formulation (which attributes are represented in models), and to the difficulty of validating models for technologies that have not yet been commercialized. Surveys, focus groups, and workshops can provide expert opinions and stated preferences of consumers (Melendez 2006). Many models rely on survey data to estimate parameters. There are known problems with the potential for bias in survey responses (Train 2009, p. 153). Respondents may give answers that systematically differ from what they would actually do in real life; they may tend to give answers they think reflect well upon them or be otherwise influenced by factors that would not arise in real-world choice situations. Careful survey design can reduce some of these problems, but the lack of sufficient sales data for advanced technology vehicles is a severe limitation to assessing barriers to the adoption of these vehicles.

Some barriers can be quantified in terms of causative variables (e.g., fraction of public who are aware of a new technology, fraction of vehicle owners who can utilize a new charging and refueling infrastructure), 
but it is difficult to relate the causes to effects (e.g., vehicle purchase decisions). Consumers vary widely in their travel needs and in their preferences and attitudes. They often consider their most demanding needs when choosing vehicles; for example, even if a consumer drives on long-distance trips only infrequently, a limited vehicle range may still present a large barrier. Therefore, average or typical driving needs and vehicle preferences may not be the basis of consumer choice in many cases. Because of this wide range of consumer preferences and the relative importance of different factors, the severity of noncost barriers ranges widely.

Some barriers are related to effects that are difficult to quantify, such as personal values, self-image, and personal interactions. Much has been written about cultural, emotional, and social aspects of car ownership and use (see, for example, Miller 2001). Certainly the symbolism of vehicles and emotional responses of consumers are important in marketing and advertising. These factors must be appreciated and understood to address barriers, but they are difficult to incorporate into a quantitative ranking of barriers. However, it is recognized that for some consumers, symbolism and emotional and social aspects can give rise to a significant preference for or dislike of certain types of vehicles or vehicle technologies, even to the extent that some consumers will not consider purchasing some of them.

Relating barrier metrics to effects such as adoption rates is needed in order to assign a magnitude or value to their severity. Even rough, approximate values can be used to rank barriers in order of their approximate severity. Table 4.1 lists the non-cost barriers discussed in this report with an order-ofmagnitude value, in dollars, representing an effective cost of the barrier, which is assigned on the basis of the discussion above. The value assigned is intended to represent the magnitude of the barrier in terms comparable to an increment in purchase price; that is, from the implied values and other considerations discussed, the dollar amounts listed represent an approximate (order of magnitude) amount that a consumer would require as compensation for accepting a vehicle in the presence of the specified barrier. Alternatively, the amount is roughly the amount a vehicle would have to be discounted in order to compensate for the barrier.

Table 4.1. Ranking of Barriers in Order of Severity

\begin{tabular}{ll}
\hline \multicolumn{1}{c}{ Non-cost Barrier } & Effective Cost \\
\hline $\begin{array}{l}\text { Limited driving range } \\
\text { Limited fueling/charging stations } \\
\text { Long fueling/charging times }\end{array}$ & $\$ 1,000$ to $\$ 10,000$ \\
$\begin{array}{l}\text { Unfamiliarity } \\
\text { Uncertainty of benefits } \\
\text { Lack of information }\end{array}$ & $\$ 100$ to $\$ 10,000$ \\
$\begin{array}{l}\text { Perceived differences or predisposition } \\
\text { Lack of adequate technology } \\
\text { standardization }\end{array}$ & $-\$ 1,000$ to $\$ 10,000$ \\
Limited availability in models/makes & Potentially $>\$ 1,000$ \\
Regulations & $\$ 100$ to $\$ 1,000$ \\
\hline
\end{tabular}

The range of the effective cost estimated is broad for all barriers, since they depend on several factors, many of which vary widely from consumer to consumer. The effective cost of range and fueling availability is judged to be clearly higher than that of other barriers, but this depends strongly on the actual vehicle range and local availability of fuel. However, it is a very large barrier to a significant fraction of consumers, many of whom would not consider a vehicle with a very limited range. "Perceived differences or predisposition" includes a variety of factors, some quite complex, but the upper end of the 
range of severity is judged to be quite high, since some consumers are predisposed against some vehicle types and may not consider purchasing them. However, some consumers may be willing to pay a price premium; hence, there is a negative lower bound for this barrier. For the barriers that are ranked as most severe, a more useful metric of severity might be the fraction of consumers willing to consider purchasing a new vehicle in the presence of the barrier. This is difficult to estimate for limited driving range, lack of fuel availability, and perceived negative difference. Unfamiliarity can also be a very high barrier, especially when it applies to consumers who are unaware of a new vehicle technology. Uncertainty of benefits and limited availability in a wide range of makes and models are significant barriers, based on the estimates discussed. Although the impacts of inadequate standards are difficult to quantify, a lack of standardization of technologies can create both cost and non-cost barriers. As discussed in the next section, the development of well-designed standards is important for preventing safety or performance problems that could lead to widespread, negative public opinions about new technologies. Regulations, as discussed below, are not judged to present significant non-cost barriers. 


\section{Policies and Programs to Lessen Non-Cost Barriers}

\subsection{Policies and Programs}

Regulatory mandates have clearly been effective in promoting the development and commercialization of new automotive technologies (e.g., Greene 1998). Historically, the approach has been to set performance standards that are technology-neutral rather than to mandate specific technologies. While fuel economy and emission regulations have sparked technological innovations and led to large improvements in fuel economy and environmental outcomes, most automobiles still rely on internal combustion engines, mechanical transmissions, and gasoline, which have been the mainstay for over 100 years. It is not clear whether mandates for increased fuel economy or even lower emissions than current standards require will move fundamentally different drivetrain technologies, such as BEVs or FCVs, into the mainstream market. Purchase incentives targeting specific technologies [e.g., tax credits for purchasing new plug-in vehicles, depending on the capacity of the battery (IRS 2009)] may be accelerating the market acceptance of plug-in vehicles considerably by lowering the cost barrier to them. The focus here, however, is on policies directed primarily to lowering non-cost barriers to the adoption of advanced technologies, especially the technologies that require some adaptations by consumers, such as plug-in or alternative fuel vehicles.

$\mathrm{R} \& \mathrm{D}$ can reduce costs of new vehicle technologies and can reduce some non-cost barriers as well, particularly the barrier of uncertainty, because as the upfront cost to consumers decreases, the risk of loss also decreases. Research, development, and testing can also reduce information uncertainty and increase confidence in the performance characteristics, safety, and ease of use of new technologies. This decreases the uncertainty-of-benefits barrier.

Other policies that are applicable to non-cost barriers include these:

- Providing incentives to introduce vehicles with new technologies in government and commercial vehicle fleets

- Developing and publicizing information on the safety, performance, and ease of use of new vehicle technologies

- Subsidizing charging and fueling infrastructure

- Providing information about new vehicle technologies through public information/education

- Supporting the development of well-designed standards and regulations.

Each of these policies is discussed in the following sections.

\subsubsection{Fleet Programs}

Introducing advanced technology vehicles into fleets offers a potentially effective way to promote advanced vehicle adoption, since (1) fleet vehicles are driven farther per year and replaced more often than private vehicles, (2) a large number of fleet vehicle purchases are made by relatively few decision makers, (3) fleet vehicle sales constitute approximately one-tenth of all light-duty vehicle sales in the United States (Davis et al. 2011), and (4) many fleets are fueled at one location. However, influencing fleet managers to purchase advanced vehicles is complicated by the heterogeneity of fleets and of fleet management and purchase decision-making practices. Nesbitt and Sperling (2001) surveyed fleet managers and observed a wide variability in fleet characteristics, including fleet size, vehicle-miles driven per year, central fueling, vehicle function (rental, delivery, service, etc.), and vehicle type (truck or car). They also observed a wide range of fleet management and purchase decision-making practices taking place among organizations. 
Nesbitt and Sperling (2001) classified the organizations that manage fleets into four types of management structure: bureaucratic, hierarchical, autocratic, and democratic. Bureaucratic organizations were largely government agencies, in which purchase decisions were hindered by bureaucratic processes and were more influenced by mandates. Such fleets tend to be large, so mandates can influence the purchase of large numbers of vehicles. They found that organizations with a hierarchical management structure tend to carefully analyze fleet purchase decisions and consider purchase and operating costs. These organizations tend to resist mandates but respond to purchase incentives. In organizations with an autocratic structure, purchase decisions are made by a small number of decision-makers, often without the benefit of in-depth analyses or information gathering from fleet associations or other fleet managers. These tend to be small entrepreneurial businesses. Purchase decisions are influenced by purchase price, by hearsay, and by learning about the experiences of contacts in similar businesses. Organizations with a democratic structure represented a small fraction of fleet managers. Purchase decisions in these organizations typically involved negotiations between interested parties within the organization but were dependent on an "idea champion" to push for a decision. Such organizations can benefit from information about advanced vehicles if the information is effectively communicated within the organization. Policies to increase the adoption of advanced technology vehicles should be designed with the diversity of fleet managers and their organizations in mind.

Policies can directly promote the purchase of advanced vehicles for government fleets. The Energy Policy Act of 1992, as amended by the Energy Conservation Act of 1998 and the National Defense Authorization Act, sets statutory requirements for the acquisition of alternative fuel vehicles by federal agencies. Starting in fiscal year $2000,75 \%$ of light-duty vehicle acquisitions in covered fleets were required to be advanced fuel vehicles. Executive Order 13423 of January 24, 2007, requires federal agencies to use PHEVs when they are commercially available at a cost reasonably comparable to that of non-PHEVs, based on life-cycle cost. More recently, the Presidential Memorandum on federal fleet performance of May 24, 2011, directs that "by December 31, 2015, all new light-duty vehicles leased or purchased by agencies must be alternative fueled vehicles, such as hybrid or electric, compressed natural gas, or biofuel. Moreover, agency alternative fueled vehicles must, as soon as practicable, be located in proximity to fueling stations with available alternative fuels, and be operated on the alternative fuel for which the vehicle is designed" (DOE Office of Energy Efficiency and Renewable Energy 2012).

Fleet incentive programs, beyond directly resulting in the purchase of vehicles by fleets, offer other benefits that could have potentially greater impacts. Fleet managers operating new technology vehicles can gain experience and provide valuable data on the reliability, on-road fuel economy, operation, and maintenance of these vehicles, and, for plug-in vehicles, valuable data on vehicle charging. Not only do fleet drivers gain direct experience with advanced technology vehicles, the general public is exposed to these vehicles as they see them in use. The programs can help raise awareness and increase familiarity with new vehicle technologies and potentially promote their consideration for private vehicle purchase. The magnitude of this benefit is very difficult to estimate but is likely to be very dependent on the duration of fleet programs; it is expected that short-term or intermittent exposure to new vehicle technologies would be ineffectual in influencing private purchases. Publicity and information campaigns can be combined with fleet purchase programs to increase this benefit.

\subsubsection{Public Information}

Public information/education efforts are valuable in addressing the familiarity and uncertainty barriers. Fuel economy labels (window stickers) inform consumers of new vehicle fuel economy ratings and estimated fuel savings; as new vehicle technologies are introduced, labels will need to provide information relevant to them as well. Providing additional information on advanced technology vehicles was, in fact, one of the motivations for the recent redesign of the label. For example, the new fuel economy and environment labels (required starting with model year 2013 vehicles) include the charging time for EVs and PHEVs and the range for EVs, PHEVs, FCVs, and compressed natural gas vehicles. The labels also provide a greenhouse gas rating, giving the emissions from the vehicle in grams of carbon 
dioxide per mile, and the labels direct consumers to the fueleconomy.gov website (DOE and U.S. Environmental Protection Agency 2011) for more information about emissions from electricity generation. At that site, users can enter their zip code to estimate emissions associated with the electricity generation used to power PHEVs or EVs in their region of the country.

More information is provided on the fueleconomy.gov website, including the fuel economy and other attributes of most passenger vehicles in the U.S. market as far back as model year 1984. The site gives not only the Environmental Protection Agency-rated fuel economy for city and highway driving cycles but also the distribution of actual fuel economy reported by owners. The fuel economy and estimated fuel cost can be personalized based on inputs from users regarding their annual driving distances, fractions of distance driven in stop-and-go traffic, and fuel prices. A side-by-side comparison of vehicles can be done easily, allowing users to compare a new vehicle with one they currently drive. The site provides background information on factors that influence fuel economy and tips for improving it. This information can reduce users' uncertainty regarding the fuel economy expected from new vehicles.

Many other outreach efforts are currently being pursued to increase the adoption of more fuel efficient and lower-emission vehicles. The Clean Cities program - the DOE Office of Energy Efficiency and Renewable Energy (EERE) transportation technology deployment program - maintains and develops a wide range of outreach and public demonstration and education activities (DOE 2012). The program establishes partnerships and collaborations with local and regional organizations to foster a network of government agencies, industry representatives, community organizations, and businesses to help partnership members combine their efforts and exchange information and resources. These include conferences, advertising, literature distribution, and public events, as well as the fueleconomy.gov website and the Alternative Fuels Data Center (AFDC) website, which provide a range of resources to support coordinators, fleets, businesses, and local decision makers (DOE AFDC 2012). The AFDC also provides detailed information on locations of alternative fueling stations. Outreach activities are tracked, and these are reported in the Clean Cities Annual Metrics Report (Johnson 2009). These efforts (particularly the fueleconomy.gov and AFDC websites) are reaching increasing numbers of people. Greene et al. (2009) made economic- and market-based estimates of petroleum savings from Clean Cities activities but did not report the effect of Clean Cities activities on adoption rates of advanced technology vehicles.

While it is difficult to quantify the effect of sustained and highly visible education and outreach programs on vehicle adoption rates, their long-term value is potentially large, since long-term market penetration by advanced vehicles appears to be sensitive to consumer awareness, as discussed in Section 4.6. Such programs need to be in place for many years to be effective. New technologies or methods designed to increase the effectiveness of public information might help, such as the personalized estimation of the benefits from driving a plug-in vehicle, as suggested by Tamor and Gearhart (2011) and discussed in Section 4.1. Other approaches targeting consumers who are considering the purchase of a PHEV are discussed in Schewel and Kammen (2010), including the use of after-market, on-board data recorders or smart phones with a virtual test drive application. The user can upload driving information to a website that provides estimates of fuel economy and fuel costs for the consumer's recorded trips for a given PHEV. These methods can provide more accurate estimates of the fuel savings offered by a PHEV, but it is unknown just how accurate these methods are. Further testing and validation would be worthwhile.

Providing information about fueling/charging station locations to drivers in their vehicles via a built-in, on-board communication/navigation system or a mobile phone is useful to those with dedicated alternative fuel vehicles or BEVs. The value of this service will increase as the fueling/charging infrastructure develops. It is difficult to estimate how influential this service is to new vehicle purchasers, however. 


\subsubsection{Subsidization of Charging and Fueling Stations}

Subsidization of charging and fueling stations is a policy that could possibly reduce the barrier of limited range and limited fuel availability. Consideration must be given to how these charging/fueling stations will be used. For plug-in vehicles, most charging is expected to be done at home, as has been observed in pilot programs. However, installing more chargers in homes does not address the range limitation barrier. Installing public chargers may reduce the range limitation barrier. Despite this, the long charging time typical of current plug-in vehicles remains a significant barrier unless the time spent charging can be spent productively by the driver. Provision of chargers at workplaces could avoid the recharging time barrier, but only to employees. The need for a public charging infrastructure and the most effective locations at which to install the charging stations are open questions that are the subject of ongoing research. Turrentine (2011) reviewed previous BEV deployment programs and noted that in many of them, public chargers were not often used. In one case, the Tokyo Electric Power Company installed public chargers and found that the BEV drivers in their fleet drove longer distances between charges after the installation of public chargers, even though the public chargers were used very little (Anagawa 2009). It may be that public chargers alleviate some range anxiety of BEV drivers, although they still prefer to charge at stations that are more convenient than public stations.

Providing adequate fueling stations for alternative fuels is essential to address the range limitation/fuel availability barrier for alternative fuel vehicles. Subsidizing alternative fueling stations is an option for reducing barriers of range limitation and fuel availability associated with alternative fuel vehicles. The density of stations required to overcome these barriers is a complex issue, as discussed in Section 4.4. Melaina and Bremson (2008) analyzed the spatial distribution of existing fueling stations in the United States and concluded that approximately 51,000 stations would provide sufficient coverage to all major urban areas. The provision of such widespread coverage would be faced with large cost barriers, even if demand for alternative fuel grew. Just how the adoption of alternative fuel vehicles might grow along with the development of the required fuel supply and distribution system would depend on local conditions, driving patterns, vehicle range, vehicle fuel economy, fuel prices, and other factors and is extremely difficult to foresee.

Research, development, and testing of new vehicle technologies could potentially allow for greater ranges, decrease refueling/recharging times, and make refueling/recharging more convenient. Improved technology and testing could also increase consumers' confidence in the safety of the technologies. If plug-in vehicles could be safely and easily charged in a few minutes rather than hours, without damaging the battery, this capability would remove the barrier due to recharging time, but obviously, a cost barrier (for the charger) could remain. It is difficult to predict the performance of future technologies and how range limitation barriers and public perceptions of new technologies will respond, but further development and evaluation are clearly essential.

\subsubsection{Technology Standardization}

Standards for hardware, communication protocols, financial transactions, and other features associated with new technologies are required for their safe and efficient deployment. Conflicting standards were a problem in some BEV deployment programs (Turrentine 2011). If consumers find new technology difficult or impossible to use because of incompatibilities or obsolescence, this will obviously present a significant barrier to adoption. DOE and DOE labs are participating with industry stakeholders to develop new standards and specifications for vehicle technologies and alternative fuels. Although well-designed standards and specifications are largely transparent to users, adequate standardization can increase the utility of new technologies and decrease uncertainty and safety concerns. Quantifying the effects of successful standardization on adoption rates of new vehicle technologies is difficult, however, since the effects are indirect (in general, consumers do not consider standards when purchasing a vehicle) and since the poor standardization can be manifested in a wide variety of problems, from minor inconvenience, to lack of functionality, to accidents that could generate widespread, negative public opinion. Although 
predicting the rates of such occurrences and their effects on public opinion is not feasible, it is clear that the successful introduction and deployment of new technologies require appropriate standards and codes. Standards for plug-in vehicles and specifications for alternative fuels and associated hardware are under development. A few of the standards for plug-in vehicle technologies are briefly described in Brown et al. (2010), and related standards are reviewed in Bohn and Chaudhry (2011). Standards, codes, and recommended safety practices relevant to hydrogen and FCVs are listed in a website maintained by EERE's Fuel Cell Technologies program (DOE 2011).

Regulations that restrict the transport of flammable, compressed gases on certain routes for safety reasons have potential implications for alternative fuels such as hydrogen or compressed natural gas. For example, New York and New Jersey have requirements that must be met by vehicles powered by natural gas or propane before they are permitted to use certain tunnels, and Indiana requires electric lanterns and prohibits flares on natural-gas-powered vehicles driven outside municipalities (DOE AFDC 2012). In general, regulations do not appear to impose a severe barrier to the use or adoption of alternative fuel vehicles. However, should hydrogen or natural gas vehicles become widely adopted, more restrictive regulations could be enacted if accidents involving alternative fuel became common. The careful development and thorough testing of vehicles, fueling and charging hardware and components, and development of appropriate safety and design standards can help reduce the chances of such accidents.

In addition to government policies that can address non-cost barriers, vehicle manufacturers and service providers are exploring new business models (e.g., shared vehicles, battery swapping, leasing of vehicles or vehicle components such as batteries) that can address them. Various approaches to providing alternative fuels, particularly electricity, are being explored by automakers, utilities, and manufacturers of EV chargers and other supply equipment. It is difficult to foresee which business models will become well-established as technology evolves.

\subsection{Effectiveness and Challenges of Policies and Programs in Addressing Non-Cost Barriers}

Strong, direct policies, such as mandates, are clearly effective in forcing technology adoption, particularly if the mandates put the responsibility on auto manufacturers, as has been the case with fuel economy and safety requirements. Additional policies can address non-cost barriers, however. Policy outcomes and effectiveness are difficult to assess, even in hindsight, and even harder to assess is the effectiveness of future policies. However, based on the nature of the non-cost barriers considered here, some conclusions may be drawn regarding the potential effectiveness of some policies in reducing these barriers as well as regarding the challenges to implementing some of these policies.

Public information, education, and outreach programs are probably effective in familiarizing both fleet managers and the general public with new vehicle technologies. It is expected that these programs will become more effective with time for two reasons: (1) Learning by doing can allow programs to improve, especially with regard to the documentation and sharing of lessons learned, and (2) the longer these programs are in effect, the greater is the number of vehicle choice decisions that can be influenced by them. The duration of education and information programs is important because the average lifetime of vehicles is long. It can be challenging to maintain strong, well-funded public information campaigns for the many years needed for such campaigns to be effective. As noted in Section 4.6, due to the slow turnover of the vehicle fleet, new advanced technology vehicles take many years to become common in the fleet, and public awareness decays rapidly without active marketing or public information. Credible information about these vehicles needs to be communicated for many years to influence many consumers.

Although fleet programs face challenges, they offer unique opportunities for evaluating how advanced technology vehicles perform under a variety of conditions and how user perceptions are formed and potentially influenced. Often it is easier to control conditions and monitor vehicle use by dealing with fleets of vehicles rather than privately owned vehicles; however, information on driver behaviors, 
attitudes, and perceptions about pilot programs is still needed from private owners. Pilot programs conducted under a wide range of conditions, in different markets, and in different countries are needed to yield a better understanding of potential markets and how they might change in the future. Pilot programs with instrumented vehicles can provide invaluable data, especially for studying the use of plug-in vehicles. The effectiveness of these programs could be large, since a better understanding of future markets is essential to design vehicles that will appeal to consumers. Without such an understanding, barriers to advanced technology vehicles may be impossible to overcome. In addition, information from fleets and pilot programs is important in providing background for public information campaigns and education programs, so they are accurate and timely.

New business models, such as car sharing or leasing, are offering alternatives to purchasing vehicles. Also, new business models for providing electricity to plug-in vehicles are evolving rapidly. Regulations on who can sell electricity might present a modest barrier to providing public chargers, but it is not clear yet what the preferred business model for pubic chargers will be. Who will pay and who will be paid for electricity, parking, and information, and to what extent electric utilities versus plug-in vehicle drivers will be able to or will choose to control the charging and use of batteries for backup power or other grid services remain to be established. However, if most plug-in vehicle drivers tend to use chargers at home or at work much more often than they use public chargers, this barrier may be modest. Appropriate standards and regulations need to be developed as new technological solutions and business models are developed. Foreseeing which new technologies will be implemented successfully, and even foreseeing how new technologies will simply be used, are difficult tasks and make it challenging to design good standards for new technologies and products.

Apart from mandates and R\&D to reduce technology costs, few public policies give incentives to automakers to offer new technologies in a wider range of makes and models. This non-cost barrier is therefore not likely amenable to policy. R\&D on modularizing designs and manufacturing might lower the costs of installing technologies in a wider range of vehicle types. Modularization is a well-established trend in vehicle manufacturing in which various vehicle types are built with common components or in which common vehicle platforms are built to use different types of drivetrains (Shamsuzzoha et al. 2010). Modularization enables greater economy of scale, which will allow a more diverse mix of vehicles to be manufactured. However, since modularization is well-established, it is not clear how much publicly funded R\&D in modularization is needed, how effective it might be, or how valuable it would be to automakers. This issue is more germane to the automaker than the policy maker. 


\section{Conclusions}

Non-cost barriers can be ranked on the basis of the assessed magnitude of their severity, as represented by an effective cost, and on the basis of the potential effectiveness of policies available to address them. Table 6.1 lists the non-cost barriers discussed in this order. Because it is so difficult to judge potential policy effectiveness, more weight was placed on the barrier's severity in assigning relative order. A negative lower bound was assigned where some consumers may be willing to pay a price premium.

Table 6.1. Non-Cost Barriers Ranked by Severity and Possible Policy Effectiveness

\begin{tabular}{|c|c|c|c|c|c|}
\hline Non-Cost Barrier & Effective Cost & Governing Factors & Possible Policies & $\begin{array}{l}\text { Potential Policy } \\
\text { Effectiveness }\end{array}$ & Policy Challenges \\
\hline \multirow{2}{*}{$\begin{array}{l}\text { Limited driving } \\
\text { range, limited } \\
\text { fueling and } \\
\text { charging stations, } \\
\text { long fueling and } \\
\text { charging times }\end{array}$} & \multirow{2}{*}{$\$ 1,000$ to $\$ 10,000$} & \multirow{2}{*}{$\begin{array}{l}\text { Vehicle's range, } \\
\text { driver's mobility } \\
\text { needs, availability } \\
\text { of home charging } \\
\text { and fueling, } \\
\text { driver's value of } \\
\text { time, availability of } \\
\text { alternatives }\end{array}$} & $\begin{array}{l}\text { Provide incentives } \\
\text { for building more } \\
\text { stations }\end{array}$ & $\begin{array}{l}\text { Probably } \\
\text { effective, if many } \\
\text { stations are built }\end{array}$ & High cost \\
\hline & & & $\begin{array}{l}\text { Pilot programs } \\
\text { (e.g., test drive, } \\
\text { fleet, lease), } \\
\text { information }\end{array}$ & $\begin{array}{l}\text { Probably } \\
\text { somewhat } \\
\text { effective }\end{array}$ & $\begin{array}{l}\text { Tailoring policies to } \\
\text { driver mobility } \\
\text { needs }\end{array}$ \\
\hline $\begin{array}{l}\text { Unfamiliarity, } \\
\text { uncertainty } \\
\text { regarding benefits, } \\
\text { lack of awareness } \\
\text { or information }\end{array}$ & $\$ 100$ to $\$ 10,000$ & $\begin{array}{l}\text { Prevalence of new } \\
\text { technology, } \\
\text { preferences of } \\
\text { early adopters }\end{array}$ & $\begin{array}{l}\text { Labeling, } \\
\text { information, } \\
\text { outreach programs }\end{array}$ & Effective & $\begin{array}{l}\text { Tailoring policies to } \\
\text { early adopters, } \\
\text { sustaining long- } \\
\text { term policies }\end{array}$ \\
\hline $\begin{array}{l}\text { Perceived } \\
\text { differences in or } \\
\text { predisposition for } \\
\text { or against } \\
\text { advanced } \\
\text { technology } \\
\text { vehicles }\end{array}$ & $\begin{array}{l}-\$ 1,000 \text { to } \\
\$ 10,000\end{array}$ & $\begin{array}{l}\text { Social and } \\
\text { behavioral factors }\end{array}$ & $\begin{array}{l}\text { Information, } \\
\text { outreach programs }\end{array}$ & Probably effective & $\begin{array}{l}\text { Tailoring policies to } \\
\text { early adopters, } \\
\text { sustaining long- } \\
\text { term policies }\end{array}$ \\
\hline $\begin{array}{l}\text { Lack of adequate } \\
\text { technology } \\
\text { standardization }\end{array}$ & $\begin{array}{l}\text { Potentially } \\
>\$ 1,000\end{array}$ & $\begin{array}{l}\text { Maturity of new } \\
\text { technologies, } \\
\text { potential for } \\
\text { incompatibilities or } \\
\text { safety issues }\end{array}$ & $\begin{array}{l}\text { Testing, standards } \\
\text { development }\end{array}$ & Effective & $\begin{array}{l}\text { Complexity of } \\
\text { technologies and } \\
\text { future business } \\
\text { models, sustaining } \\
\text { testing and } \\
\text { standardization } \\
\text { efforts }\end{array}$ \\
\hline $\begin{array}{l}\text { Limited availability } \\
\text { and diversity of } \\
\text { makes and models }\end{array}$ & $\$ 100$ to $\$ 1,000$ & $\begin{array}{l}\text { Consumer } \\
\text { preferences, } \\
\text { modularization of } \\
\text { design and } \\
\text { manufacturing }\end{array}$ & $\begin{array}{l}\text { R\&D on } \\
\text { modularization }\end{array}$ & Limited & $\begin{array}{l}\text { Limited role for } \\
\text { public policy }\end{array}$ \\
\hline Regulations & Minor & $\begin{array}{l}\text { Requirements or } \\
\text { restrictions unique } \\
\text { to advanced } \\
\text { technology } \\
\text { vehicles }\end{array}$ & * & * & * \\
\hline
\end{tabular}

${ }^{*}$ Regulatory reforms were not considered due to the low magnitude of this barrier

This table represents only one such ranking of non-cost barriers. Obviously the actual severity of any barrier or the effectiveness of any policy will depend highly on factors specific to an individual situation, 
so assigning a single number to any barrier is an oversimplification. This is why the estimates of effective cost vary so widely. For the most severe barriers, another metric might be the potential size of the market for vehicles faced with given barriers, but this is difficult to estimate for new vehicle technologies. This may be more appropriate at the vehicle level (i.e., for technology packages in specific vehicle types) rather than at the barrier level. More fundamentally, a more comprehensive (and probably more useful) metric would be the benefit-to-cost ratio net present value, if costs and benefits could be estimated over the duration of policy implementation. This would require defining the scope of costs and benefits and developing methods for their estimation, neither of which was attempted for this report.

The ranking in Table 6.1 suggests barriers that are most severe and that might be addressed by the policies considered. It is not intended to suggest that addressing the top-ranked barriers would provide the greatest benefit or should be pursued at the expense of efforts to address other non-cost barriers.

The adoption of new vehicle technologies by consumers depends on many diverse factors. The desire for high fuel economy varies widely from consumer to consumer and depends on many influences that are difficult to completely identify or quantify. Research on consumers' vehicle purchase behavior has indicated that important factors that influence purchase decisions (besides vehicle price) include limited vehicle range and fuel availability (if these are significantly less than those of conventional vehicles), unfamiliarity and uncertainty, consumers' perceptions and predispositions, limited availability of advanced technology vehicles, and, potentially, the lack of adequate technology standards. These barriers were deemed to be the most significant non-cost barriers to adopting the vehicle technologies currently being developed, judging from recent studies of consumer behavior. In the future, consumers' vehicle purchase behavior, travel behavior, vehicle ownership patterns, and attitudes toward vehicle use may change significantly, and future vehicle technologies may be quite different, resulting in new barriers or a lessening of existing barriers. Further work to better understand these barriers will be important in promoting new vehicle technologies and in planning their development. 


\section{Appendix: Market Shares ANd Implied Value in Nested, MULTINOMIAL LOGIT MODELS}

Multinomial logit discrete choice models have the property that the ratio of probability of any two choices is independent of the attributes of the other alternatives. This is the property of "independence from irrelevant alternatives" (IIA). In reality, there may be dependence; for example, if consumers have preferences for certain classes or types of vehicles, the choice probability should depend on the presence or absence of attributes in different classes. Nested, multinomial logit models are a generalization of multinomial logit models that allow alternatives to be nested, so that alternatives within a nest have the IIA property, while for alternatives in different nests, the ratio of probabilities of choices can depend on the attributes of other alternatives in the two nests (IIA does not hold). This allows more realistic substitution patterns to be modeled.

Equation 3 in Section 3.1, which relates the price coefficient in a utility function to vehicle price, price elasticity of demand, and market share, is valid for multinomial logit models but does not hold for nested multinomial logit models. The result is that with nesting, implied values of barriers between two choices within the same nest are smaller than - and implied values of barriers between two choices in different nests are larger than - the implied value given by Equation 3. For example, if an attribute is offered by only one type of vehicle, such as cars, the barriers to adoption of vehicles that have such an attribute would be lower to consumers who prefer cars and higher to consumers who prefer pickups.

The appropriate value for the price elasticity therefore depends on the context of the vehicle choice. For example, if the question is "What alternative fuel vehicle will consumers purchase?", the elasticity for the alternative fuel vehicle segment should be used, which will typically be larger in magnitude than the elasticity for the light-duty vehicle segment. Greene (2001) reviewed literature on price elasticity of demand for vehicle market segments and reported average values of "own price elasticity of demand" for car size classes; these ranged from -1.7 to -3.4 at a market share of 0.5 and from -2.4 to -4.7 for makes and models. In nested multinomial logit models, vehicle choices are grouped into "nests," each with its own set of coefficients, including its own price coefficient. The appropriate price coefficient and therefore the implied value depend on the vehicle choice of interest. For example, the implied value of fueling station availability will be different to the purchaser of a general vehicle than the purchaser of an alternative fuel vehicle, given that the consumer will choose an alternative fuel vehicle. Care must be taken in defining the context of a barrier, and the correct coefficients must be used in estimating implied values.

An additional clarification is that the elasticity as given in Equation 3 is the price elasticity of demand only in a model in which alternatives include an "outside good" (i.e., a not buying a car). In models that do not include such an alternative, the numerator in Equation 3 is the elasticity of substitution. 


\section{REFERENCES}

Anagawa, T. 2009. "Desirable Characteristics of Public Quick Charger," PHEV09 Montreal, September. Accessed December 1, 2011: http://emc-mec.ca/phev/Presentations en/S12/PHEV09-S12-

3_TakafumiAnegawa.pdf

Bandivadekar, A., K. Bodek, L. Cheah, C. Evans, T. Groode, J. Heywood, E. Kasseris, M. Kromer, M. Weiss. 2008. On the Road in 2035, Laboratory for Energy and the Environment, Massachusetts Institute of Technology report LFEE 2008-05 RP: http://web.mit.edu/sloan-auto-lab/research/beforeh2/otr2035/

Bohn, T., H. Chaudhry. 2011. "Overview of SAE Standards for Plug-in Electric Vehicle," Innovative Smart Grid Technologies (ISGT) Conference, Washington, DC, Jan. 16-20, 2012. Accessed September 28, 2012: http://ieeexplore.ieee.org/stamp/stamp.jsp?tp=\&arnumber=6175597.

Brown, S., D. Pyke, P. Steenhof. 2010. "Electric Vehicles: The Role and Importance of Standards in an Emerging Market," Energy Policy 28, pp. 3797-3806.

Brownstone, D., D. Bunch, K. Train. 2000. "Joint Mixed Logit Models of Stated and Revealed Preferences for Alternative-Fuel Vehicles," Transportation Research Part B 34, pp. 315-338.

Cherchi, E. 2009. "Modelling Individual Preferences: State of the Art, Recent Advances and Future Directions," 12th International Conference on Travel Behavior Research, Jaipur, India, Dec. 13-19. Accessed September 14, 2011: http://iatbr2009.asu.edu/ocs/custom/resource/W5 R1 Modelling\%20individual\%20preferences, $\% 2$ 0State $\% 20$ of $\% 20$ the $\% 20$ art.pdf.

Choo and Mokhtarian. 2004. "What Type of Vehicle Do People Drive? The Role of Attitude and Lifestyle in Influencing Vehicle Type Choice," Transportation Research Part A 38, pp. 201-222.

Collantes, G. 2010. "Do Green Tech Policies Need to Pass the Consumer Test? The Case of Ethanol Fuel," Energy Economics 32, pp. 1235-1244.

Davis, S.C., S.W. Diegel. 2007. Transportation Energy Data Book, 27th Edition, ORNL-6981, Oak Ridge National Laboratory, Oak Ridge, Tenn.

Davis, S.C., S.W. Diegel, R.G. Boundy. 2010. Transportation Energy Data Book, 29th Edition, ORNL6985, Oak Ridge National Laboratory, Oak Ridge, Tenn.

Davis, S.C., S.W. Diegel, R.G. Boundy. 2011. Transportation Energy Data Book, 30th Edition, ORNL6986, Oak Ridge National Laboratory, Oak Ridge, Tenn. Accessed January 10, 2012: http://cta.ornl.gov/data/index.shtml.

Dixit, A.K., R.S. Pindyck. 1994. Investment under Uncertainty, Princeton, N.J.: Princeton University Press.

DOE (U.S. Department of Energy). 2011. Safety, Codes \& Standards. Accessed December 2, 2011: http://www1.eere.energy.gov/hydrogenandfuelcells/codes/.

DOE. 2012. Clean Cities. Accessed September 28, 2012: http://www1.eere.energy.gov/cleancities/index.html.

DOE and EPA (U.S. Environmental Protection Agency). 2011. Fuel Economy. Accessed November 20, 2011: www.fueleconomy.gov.

DOE AFDC (Advanced Vehicles Data Center). 2012. Alternative Fueling Station Locator. Accessed August 16, 2012: http://www.afdc.energy.gov/.

DOE Office of Energy Efficiency and Renewable Energy. 2012. Sustainable Federal Fleets. Accessed August 16, 2012: https://federalfleets.energy.gov/federal_requirements/fleet_requirements/by topic 
EV Project. 2012. The EV Project. Accessed May 29, 2012: http://www.theevproject.com/index.php.

FHWA (Federal Highway Administration). 2005. 2001 National Household Travel Survey.

U.S. Department of Transportation. Accessed November 17, 2011: http://nhts.ornl.gov/.

FHWA. (undated). NHTS Tables: Online Analysis Tools: Table Designer. Accessed February 14, 2011: http://nhts.ornl.gov/tables09/ae/TableDesigner.aspx.

Greene, D.L. 2011. “Uncertainty, Loss Aversion, and Markets for Energy Efficiency,” Energy Economics 33, pp. 608-616.

Greene, D.L. 2010. How Consumers Value Fuel Economy: A Literature Review, EPA-420-R-10-008, U.S. Environmental Protection Agency, March. Accessed December 5,

2011: http://www.epa.gov/otaq/climate/regulations/420r10008.pdf.

Greene, D.L. 2001. TAFV Alternative Fuels and Vehicles Choice Model Documentation, ORNL/TM2001/134, Oak Ridge National Laboratory, Oak Ridge, Tenn. Accessed February 11, 2011: http://www.ornl.gov/ webworks/cppr/y2001/rpt/111293.pdf.

Greene, D.L. 1998. "Why CAFE Worked,” Energy Policy 26, pp. 595-613.

Greene, D.L., R. Gibson, J.L. Hopson. 2009. Reducing Oil Use and $\mathrm{CO}_{2}$ Emissions by Informing Consumers' Fuel Economy Decisions: The Role for Clean Cities, prepared for the U.S. Department of Energy, Office of Energy Efficiency and Renewable Energy, by Oak Ridge National Laboratory, Oak Ridge, Tenn., August. Retrieved December 11, 2011: http://www1.eere.energy.gov/cleancities/pdfs/fuel economy strat paper.pdf.

Heffner R., K.S. Kurani, T.S. Turrentine. 2007. Symbolism in Early Markets for Hybrid Electric Vehicles, Institute of Transportation Studies, University of California at Davis. Accessed February 9, 2011: http://pubs.its.ucdavis.edu/publication detail.php?id=1063.

Helfand, G., A. Wolverton. 2009. "Evaluating the Consumer Response to Fuel Economy: A Review of the Literature," Working Paper 09-04, National Center for Environmental Economics, U.S. Environmental Protection Agency, Washington, D.C., August. Accessed December 5, 2011: http://yosemite.epa.gov/EE/Epa/eed.nsf/44a8be610f6c5f0885256e46007b104e/51a36d18d3ef67b9 8525761c004dfa5e/\$FILE/2009-04.pdf.

Hidrue, M.K., G.R. Parsons, W. Kempton, M. Gardner. 2010. "Willingness to Pay for Electric Vehicles and Their Attributes," Energy and Resource Economics 33, pp. 686-705.

IRS (Internal Revenue Service). 2009. "New Qualified Plug-in Electric Drive Motor Vehicle Credit," Internal Revenue Bulletin 2009-48, November 30. Accessed June 22, 2012: http://www.irs.gov/irb/200948 IRB/ar09.html.

Johnson, C. 2009. Clean Cities Annual Metrics Report 2009 (Revised), NREL/TP-7A20-49389, National Renewable Energy Laboratory. Accessed September 28, 2012: http://www1.eere.energy.gov/cleancities/pdfs/49389.pdf.

Kleit, A.N. 1990. "The Effect of Annual Changes in Automobile Fuel Economy Standards," Journal of Regulatory Economics 2, pp. 151-172.

Kurani, K.S., J. Axsen, N. Caperello, J. Davies-Shawhyde, P. Dempster, M. Kempster, K.A. Nesbitt, T. Stillwater. 2010. Plug-In Hybrid Electric Vehicle (PHEV) Demonstration and Consumer Education, Outreach, and Market Research Program: Volumes I and II, University of California at Davis, November. Accessed January 27, 2012: http://pubs.its.ucdavis.edu/publication detail.php?id=1424.

Larrick, R.P., J.B. Soll. 2008. “The MPG Illusion,” Science 320, pp. 1593-1594. 
Li, S. 2010. "Traffic Safety and Vehicle Choice: Quantifying the Effects of the 'Arms Race' on American Roads," Journal of Applied Econometrics, February, published online, doi 10.1002/jae.1161.

Lin, Z., D.L. Greene. 2010a. “A Plug-in Hybrid Consumer Choice Model with Detailed Market Segmentation," Transportation Research Board 2010 Annual Meeting, CD-

ROM. http://cta.ornl.gov/dta/index.shtml.

Lin, Z., D.L. Greene. 2010b. "Rethinking FCV/BEV Vehicle Range: A Consumer Value Trade-off Perspective," EVS-25, The 25th World Battery, Hybrid and Fuel Cell Electric Vehicle Symposium \& Exhibition, Shenzhen, China, November 5-9.

Lin, Z., D.L. Greene. 2011. "Promoting the Market for Plug-in Hybrid and Battery Electric Vehicles: The Role of Recharge Availability," Transportation Research Record 2252, pp. 49-56.

Lin, Z., J. Dong, C. Liu, D. Greene. 2012. "PHEV Energy Use Estimation: Validating the Gamma Distribution for Representing the Random Daily Driving Distance," Transportation Research Board 2012 Annual Meeting. http://pubsindex.trb.org/view/2012/C/1129781.

Melaina, M., J. Bremson. 2008. "Refueling Availability for Alternative Fuel Vehicle Markets: Sufficient Urban Station Coverage," Energy Policy 36, pp. 3,233-3,241.

Melendez, M. 2006. Transitioning to a Hydrogen Future: Learning from the Alternative Fuels Experience, NREL/TP-540-39423, National Renewable Energy Laboratory. Accessed February 16, 2011: http://www.nrel.gov/hydrogen/pdfs/39423.pdf.

Miller, D. (ed.). 2001. Car Cultures, New York, N.Y.: Berg.

Nesbitt, K., D. Sperling. 2001. "Fleet Purchase Behavior: Decision Processes and Implications for New Vehicle Technologies and Fuels," Transportation Research Part C, pp. 297-318.

Pearre, N.S., W. Kempton, R.L. Guensler, V.V. Elango. 2011. "Electric Vehicles: How Much Range Is Required for a Day's Driving?” Transportation Research Part C 19, pp. 1171-1184.

Santini, D.J., A.D. Vyas. 2005. Suggestions for a New Vehicle Choice Model Simulating Advanced Vehicles Introduction Decisions (AVID): Structure and Coefficients, ANL/ESD/05-1, Argonne National Laboratory, Argonne, Ill. Accessed September 28, 2012: http://www.transportation.anl.gov/pdfs/TA/350.pdf.

Schewel, L., D. Kammen. 2010. "Smart Transportation: Synergizing Electrified Vehicles and Mobile Information Systems," Environment: Science and Policy for Sustainable Development 52, pp. 24-35.

Shamsuzzoha, A., P.T. Helo, T. Kekale. 2010. "Application of Modularity in World Automotive Industries: A Literature Analysis,"

Small, K.A., E.T. Verhoef. 2007. The Economics of Urban Transportation, New York: Routledge.

Sperling, D., R. Kitamura. 1986. "Refueling and New Fuels: An Exploratory Analysis," Transportation Research A 20A, pp. 15-23.

Sperling D., K.S. Kurani. 1987. "Refueling and the Vehicle Purchase Decision: The Diesel Car Case," SAE Technical Paper 870644, Society of Automobile Engineers.

Stephan, C.H., J.L. Sullivan. 2004. "The Growth of Hydrogen Transportation Infrastructure," Proceedings of the Agent 2004 Conference on Social Dynamics: Interaction, Reflexivity and Emergence, ANL/DIS-05-6, sponsored by Argonne National Laboratory, Argonne, Ill., held at The University of Chicago, October 7-9. Accessed September 27, 2012:

http://www.e-du.nl/frontiers/2005/discussion/documents/Stephan_Agent04.pdf. 
Struben, J.J.R. 2006. "Essays on Transition Challenges for Alternative Propulsion Vehicles and Transportation Systems, Economic Models Using Bottom-up Information,” Ph.D. dissertation, Massachusetts Institute of Technology. Accessed November 21, 2011: http://dspace.mit.edu/bitstream/handle/1721.1/37159/85835878.pdf? sequence=1.

Struben, J.J.R., J.D. Sterman. 2007. "Transition Challenges for Alternative Fuel Vehicle and Transportation Systems," MIT Sloan Research Paper 4587-06, Massachusetts Institute of Technology, Sloan School of Management, May, http://ssrn.com/abstract=881800.

Tamor, M., C. Gearhart. 2011. "An Analytic Method for Estimation of Electric Vehicle Range Requirements, Electrification Potential and Prospective Market Size," presented at the 2011 Asilomar Biennial Conference on Transportation and Energy, August 29-September 1, http://www.its.ucdavis.edu/files/general/pdf/2012-08-21_Asilomar-Tamor-2011.pdf.

Tompkins, M.D., D.S. Bunch, D. Santini, M. Bradley, A. Vyas, D. Poyer. 1998. "Determinants of Alternative Fuel Vehicle Choice in the Continental United States," Transportation Research Record 1641, pp. 130-138.

Train, K.E. 2009. Discrete Choice Methods with Simulation, 2nd Edition, New York, N.Y.: Cambridge University Press.

Turrentine, T. 2011. Market Deployment of Electric Vehicles: Lessons Learned, Presentation P11-0968, Transportation Research Board 90th Annual Meeting, Washington, D.C., January 23-27.

USHUD (U. S. Department of Housing and Urban Development). 2006. American Housing Survey for the United States: 2005. Accessed June 18, 2010: http://www.google.com/url? sa=t\&source=web\&cd=2\&ved=0CB0QFjAB\&url=http $\% 3 \mathrm{~A} \% 2 \mathrm{~F} \% 2 \mathrm{~F}$ www.census.gov $\% 2$ Fprod $\% 2$ F2006pubs $\% 2 F h 150-05$.pdf\&ei $=\mathrm{K}-$ dWTNeOOsi9ngeyl7XiBQ\&usg=AFQjCNF-1Yoc6DGDK4VPwjfDdWG-NW-41Q.

Vyas, A.D., J. Santini, L.R. Johnson. 2009. "Potential of Plug-in Hybrid Electric Vehicles to Reduce Petroleum Use: Issues Involved in Developing Reliable Estimates," Transportation Research Record 2139 , pp. 55-63. 


\section{u.s. DePARTMENT OF | Energy Efficiency \& Renewable Energy}

Prepared by ANL for the U.S. Department of Energy

The Transportation Energy Futures Series is a joint project of the National Renewable Energy Laboratory (NREL) and Argonne National Laboratory (ANL), national laboratories of the U.S. Department of Energy, Office of Energy Efficiency and Renewable Energy.

DOE/GO-102013-3709 • March 2013

eere.energy.gov/analysis/transportationenergyfutures

Printed with a renewable-source ink on paper containing at least $50 \%$ wastepaper, including $10 \%$ post consumer waste. 